Regular Article

\title{
Selective removal of over-paintings from "Street Art" using an environmentally friendly nanostructured fluid loaded in highly retentive hydrogels
}

\author{
Michele Baglioni ${ }^{\mathrm{a}, 1}$, Giovanna Poggi ${ }^{\mathrm{a}}$, Rodorico Giorgi ${ }^{\mathrm{a}, *}$, Paola Rivella ${ }^{\mathrm{a}}$, Taku Ogura ${ }^{\mathrm{c}, \mathrm{d}, \mathrm{e}}$, Piero Baglioni ${ }^{\mathrm{b}, 1, *}$ \\ ${ }^{a}$ Department of Chemistry, University of Florence, via della Lastruccia, 3, 50019, Sesto Fiorentino, FI, Italy \\ ${ }^{\mathrm{b}}$ CSGI, Center for Colloids and Surface Science, University of Florence, via della Lastruccia, 3, 50019, Sesto Fiorentino, FI, Italy

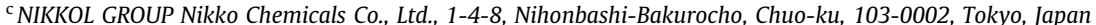 \\ ${ }^{\mathrm{d}}$ NIKKOL GROUP Cosmos Technical Center Co., Ltd., 3-24-3 Hasune, Itabashi-ku, 174-0046, Tokyo, Japan \\ ${ }^{\mathrm{e}}$ Research Institute for Science \& Technology, Tokyo University of Science, 2641, Yamazaki, Noda-shi, Chiba 278-8510, Japan
}

\section{H I G H L I G H T S}

- Tags and writings on street art are vandalism and should be carefully removed.

- Over-paintings selective removal cannot be achieved with conventional methodologies.

-Water-based low-toxicity, ecocompatible nanostructured fluids have been developed.

- Nanostructured fluids can selectively clean graffiti from over-paintings.

\section{A R T I C L E I N F O}

\section{Article history:}

Received 16 February 2021

Revised 9 March 2021

Accepted 10 March 2021

Available online 26 March 2021

\section{Keywords:}

Paints

Over-paintings

Graffiti

Street art

Cleaning

Nanostructured fluids

Alkyl carbonates

Surfactants

Hydrogels

\section{G R A P H I C A L A B S T R A C T}
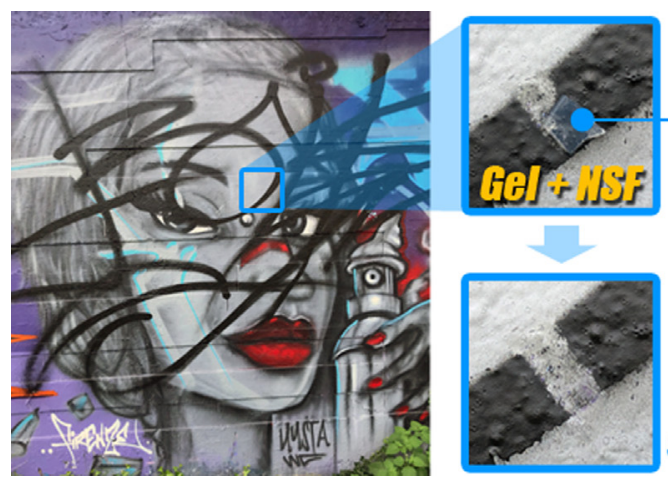

NSF characterization

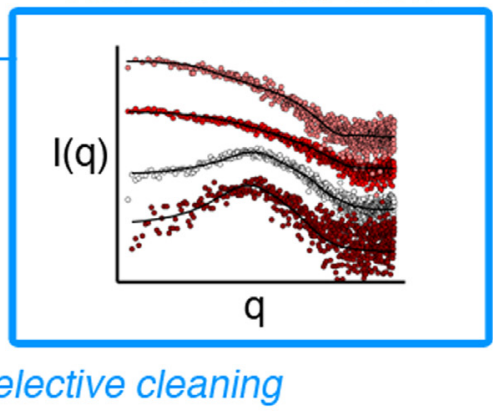

\footnotetext{
* Corresponding authors.

E-mail addresses: rodorico.giorgi@unifi.it (R. Giorgi), baglioni@csgi.unifi.it (P. Baglioni).

${ }^{1}$ No kinship exists among these authors.
} 
Findings: The selective and controlled removal of modern paints from substrates with similar chemical composition has been achieved using a specifically tailored NSF embedded in a retentive hydrogel. The proposed methodology and cleaning system provided excellent cleaning results, representing a new tool for the conservation of contemporary and, in particular, street art.

(c) 2021 Elsevier Inc. All rights reserved.

\section{Introduction}

Selective removal of over-paintings is a well-known issue in conservation of cultural heritage and nowadays is gaining a growing attention due to street art, i.e., the expression of unconventional artists/writers such as Eduardo Kobra [1], Banksy [2] and many others. In a number of cities around the world there are streets completely devoted to street art, where the artists can produce their graffiti, which are continuously renewed and over-painted. This is the case, for instance, of Graffiti Alley, in Cambridge, MA (USA), whose walls are covered in pieces of street art, and which represents a sort of ever-evolving permanent art exposition. In this context, in view of graffiti growing economic and artistic interest, it is generally recognized that these works of art, originally drawn to last no more than some months or years, should be preserved. Thus, tags and writings that may cover pieces of street art are treated as actual vandalism and have to be carefully and promptly removed. In fact, the vandalization of paintings with writings, drawings or other figurative and jeopardizing additions can be regarded, in general, as the main reason for the need of a thorough research on innovative and effective methodologies for selective and controlled cleaning. This is a novel topic in conservation of cultural heritage dealing with the removal of modern or contemporary paint layers from the same or similar materials, which were often applied on unsuitable substrates and not intended to last through time. Common methodologies for the removal of graffiti from stony substrates can be divided in two main classes: chemical and physical methods [3]. Chemical cleaning, performed with organic solvents or solvents mixtures, usually combined with some mechanical action, is the main method for this purpose [3]. Alternatively, physical methodologies can be used. These include traditional tools, such as scalpels, abrasive media, and water or sand blasting [35], and more innovative approaches, such as laser ablation, ultrasonication, plasma spray, arc or thermal spray, dry ice blasting and soda blasting [3-13]. However, none of these techniques (except for laser ablation, and in some specific cases) guarantees a controlled removal action. In fact, the key for the selective removal of over-paintings is to limit the cleaning action to a few microns $(10-100 \mu \mathrm{m})$ in depth, to remove the top undesired paint layer with no damages or alterations of the original painting. The selectivity of laser cleaning is mainly due to the different absorption of radiation of the material to be removed with respect to the original substrate. Therefore, the majority of specific applications are related to the removal of undesired materials (polymer coatings, varnishes, alteration patinae, black crusts) from completely different substrates, i.e. stones [14-20], metals [21], but even wood [22] or paper $[23,24]$. Conversely, the usually poor optical absorption and low thermal conductivity of paints make the use of laser for the removal of graffiti [25] or over-paintings [26-28] from paint layers quite difficult and time consuming, even if some positive results were recently obtained in the removal of over-paintings from oil paintings [28].

Nanostructured fluids (NSFs) and solvents confined in chemi$\mathrm{cal} /$ physical gels are used in the conservation of cultural heritage due to their effectiveness in the removal of several materials, i.e., wax and hydrophobic concretions [29-31], polymer coatings [32-36], varnishes [37], etc., from different works of art (such as
Renaissance fresco paintings), removal of pressure sensitive tapes [38-40], cleaning of masterpieces as Beato Angelico, Picasso [41], Pollock [42], Lichtenstein [43] and many others [44]. NSFs are mainly aqueous systems (i.e. water amount is usually comprised between $60 \%$ and $90 \% \mathrm{w} / \mathrm{w}$ ) with reduced toxicity and increased control on the cleaning action with respect to neat unconfined organic solvents. It is worth to notice that NSFs mechanism of action depends on the nature of the materials to be removed from the works of art. For example: when NSFs are used to remove materials composed by small hydrophobic molecules, the cleaning usually follows the detergency solubilization process, and the undesired compound may be solubilized into the non-polar core of the droplets constituting the complex fluid [45]. Conversely, polymer coatings or other high-molecular weight compounds are usually dewetted by NSFs [30,46-51]. Recently, to improve the performance and control of the cleaning action, nanostructured fluids (NSFs), based on ionic surfactants, have been confined in semi-interpenetrated polymer networks (SIPN), whose structure is based on poly(hydroxyethyl methacrylate)/poly(vinyl pyrrolidone), pHEMA/PVP, or poly(vinyl alcohol), PVA, having different degree of hydrolysis. The latter constitute a new class of gels, also known as twin-chain polymer networks (TCPN) since they are formed through a liquid-liquid phase separation of polymers differing in their hydrolysis degree and MW, only [42].

Highly-retentive hydrogels, such as pHEMA/PVP SIPN and twinchain polymer networks grant the maximum control on the cleaning action, by limiting the evaporation, penetration and lateral spreading of the confined fluid [52-57]. Their formulation can be modified in order to tune their liquid release rate, making them highly suitable for cleaning in a very controlled fashion, as in the case of removal of over-paintings. The excellent results recently obtained can be considered as a proof of concept of the possible selective removal of over-paintings of acrylic layers from chemically similar or equal acrylic paint layers [58].

In this paper, we report, to the best of our knowledge, the first systematic study on the selective and controlled removal of modern paints from substrates with similar chemical composition. The main classes of binders of modern and contemporary commercial paints, i.e., vinyl, acrylic and alkyd polymers, have been considered in the present paper. Several commercial paints were selected and characterized by means of ATR-FTIR and solubility tests were performed with neat solvents having different polarity. On the basis of the results of solubility tests, the components were selected to formulate a new NSF, i.e., an "o/w microemulsion" based on alkyl carbonates, which are green low-toxicity organic solvents, and on biodegradable nonionic surfactants.

Over the last few decades, alkyl carbonates have been increasingly employed as useful solvents in industrial processes, due to their good and versatile properties [59]. These are known to be non-toxic and low-impact organic solvents, produced via transesterification reactions of alcohols and polyols, which also are relatively safe and eco-compatible. Four alkyl carbonates were selected, i.e., propylene carbonate, dimethyl carbonate, diethyl carbonate, and dibutyl carbonate. The NSF set up followed a detailed study on the phase diagram of alkyl carbonates in mixture with water and an ethoxylate surfactant. Shape, size and size distribution of supramolecular aggregates present in the NSF were charac- 
terized by means of small angle X-ray scattering (SAXS). This information is important to know whether the proposed cleaning fluid can be loaded into the hydrogel for a controlled and residue-free cleaning action. The NSF/hydrogel combined system was then tested for the selective removal of acrylic, vinyl and alkyd paints layers from painted layers of the same chemical nature, considering all the possible layers combinations. FTIR was used to evaluate the results of selective cleaning tests, together with photographic documentation. Finally, in situ tests performed on a real piece of street art, allowed the assessment of the proposed methodology.

\section{Experimental section}

\subsection{Chemicals}

Propylene carbonate (PC; Sigma-Aldrich, assay 99\%), $\mathrm{C}_{12-14} \mathrm{E}_{9}$ alcohol ethoxylate surfactant (NIKKO Chemicals, assay 99\%), 2butanol (BuOH, Sigma-Aldrich, assay 99\%), dimethyl carbonate (DmC, Sigma-Aldrich, assay 99\%), diethyl carbonate (DeC, SigmaAldrich, assay > 99\%), dibutyl carbonate (DbC, Massimo Guarducci s.r.l., assay $>98 \%$ ), acetone (Ac, Sigma-Aldrich, assay $>99.5 \%$ ), ethanol (EtOH, Sigma-Aldrich, assay > 99.8\%), p-xylene (Xyl, SigmaAldrich, assay > 99\%), cyclohexane $(\mathrm{CH}$, Sigma-Aldrich, assay 99.5\%), AG 6206 alkyl glycoside (AG6206, Akzo Nobel, assay N. A.), 2-hydroxyethyl methacrylate (HEMA; Sigma-Aldrich, assay 97\%), poly(vinyl pyrrolidone) (PVP; Sigma-Aldrich, average Mw $\approx 1300 \mathrm{kDa}$ ), $\alpha, \alpha^{\prime}$-azoisobutyronitrile (AIBN; Fluka, assay 98\%), and N,N-methylene-bisacrylamide (MBA; Fluka, assay 99\%) were used as received. Water was purified using a Millipore MilliRO-6 and MilliQ (Organex Systems) apparatus (resistance $>18 \mathrm{M} \Omega$ $\mathrm{cm})$. Sand (50-70 mesh particle size) was purchased from SigmaAldrich, and aged slaked lime was purchased from La Banca della Calce s.r.l., Bologna, Italy.

\subsection{Paints}

Professional grade artists' modern tube paints were used in this work. The selected paints can be divided in three classes of binders (vinyl-, acrylic- and alkyd-based): Orient Red (vinyl-based, Flashe Lefranc Bourgeois), White 01 (vinyl-based, Flashe - Lefranc Bourgeois), Phtalocyanine Green (acrylic-based, Heavy Body - Liquitex), Titanium White (acrylic-based, Heavy Body - Liquitex), French Ultramarine (alkyd-based, Griffin - Winsor \& Newton), Titanium White (alkyd-based, Griffin - Winsor \& Newton). The paints were purchased and used as received, without dilution.

\subsection{Samples preparation}

One part of slaked lime and three parts of sand were mixed to prepare mortar mockups. The mixture was then poured into wooden molds of $5 \times 5 \times 1.5 \mathrm{~cm}^{3}$ and left setting for 1 month. Some of the obtained tiles were painted with single layers of the six paints selected for this study to perform some preliminary tests. The remaining tiles were used for the selective removal tests by covering them with two superimposed layers of paint. These tiles were painted with a layer of blue (alkyd), red (vinyl) or green (acrylic) paint and let dry until complete evaporation of solvent. Finally, the white (alkyd, vinyl or acrylic) paint was laid over the colored one, leaving a reference square uncovered. Removal tests were performed 2 weeks later, after complete setting. All the possible combinations were evaluated, and the final set of samples, with their labels, is reported in Table 1.

\subsection{Solubility and preliminary cleaning tests}

Solubility tests were performed by immersing about $8 \mathrm{mg}$ of each paint used in this study in $2 \mathrm{ml}$ of the selected liquids, i.e., four alkyl carbonates (propylene carbonate, dimethyl carbonate, diethyl carbonate, and dibutyl carbonate), and a selection of reference solvents, commonly used in conservation, i.e., water, ethanol, 2-butanol, acetone, xylene and cyclohexane. The samples were equilibrated at room temperature $\left(\approx 20^{\circ} \mathrm{C}\right)$ and analyzed by visual observation and photographic documentation. Preliminary cleaning tests on the six single-layer selected paints were performed by means of cotton swabs soaked with the same solvents, in order to check for paints' removability when mechanical action is coupled to coating solubilization.

\section{5. pHEMA/PVP hydrogels synthesis}

The pHEMA/PVP SIPN hydrogels were prepared as 2-mm thick sheets, following a procedure reported elsewhere [52] by physically embedding linear PVP into the 3D pHEMA/MBA network, obtained by free radical polymerization of the HEMA monomer and MBA cross-linker in a water solution containing high molecular weight PVP. These hydrogels can be designed by varying their component ratios in order to tune their characteristics in terms of mechanical behavior and hydrophilicity. In our study the gel formulation was set as follows: water 57.8\%; PVP, 25\%; HEMA, 16.8\%; MBA, $0.2 \%$; AIBN, $0.2 \%$. The polymerization reaction, initiated by thermal homolysis of AIBN, was carried out in molds kept in oven at $60{ }^{\circ} \mathrm{C}$ for $4 \mathrm{~h}$. The obtained hydrogels sheets were washed and stored in containers filled with water.

\subsection{NSF formulation}

To obtain the final NSF composition, the miscibility gap of water/alkyl carbonate mixtures was investigated over the 10$80{ }^{\circ} \mathrm{C}$ temperature range for propylene carbonate, dimethyl carbonate, diethyl carbonate, and dibutyl carbonate. In order to obtain information on the surfactant effect, ternary phase diagrams of water $/ \mathrm{C}_{12-14} \mathrm{E}_{9} /$ alkyl carbonate were studied. Propylene carbonate and diethyl carbonate were selected as candidate solvents for the NSF. Beside the nonionic surfactant, AG6206 was added to the system as a stabilizing hydrotrope, and $\mathrm{BuOH}$ was added as a cosurfactant/cosolvent. Thus, the final composition of the NSF used for the application was formulated by investigating a significant portion of the water $-\mathrm{C}_{12-14} \mathrm{E}_{9} / \mathrm{BuOH} / \mathrm{AG} 6206$ (5.6: $2.8: 1 \mathrm{w} / \mathrm{w}$ ) - PC/ $\operatorname{DeC}(1: 1 \mathrm{w} / \mathrm{w})$ pseudo-ternary phase diagram to obtain a stable single-phase system, maximizing the amount of organic solvents, limiting the amount of surfactant. The composition of the selected NSF for the cleaning tests is: water, $60.9 \%$; $\mathrm{C}_{12-14} \mathrm{E}_{9}, 14.7 \%$; AG6206, 2.6\%; $\mathrm{BuOH}, 7.3 \%$; PC, 7.3\%; DeC, 7.3\%. The samples investigated to build up the phase diagrams of the present study are reported in the supporting information file (Figures S1, S2, and S3).

\subsection{Laboratory cleaning tests}

Laboratory selective removal tests were performed with the NSF-loaded pHEMA/PVP gel. A small piece of gel (about $8 \times 8 \times 2 \mathrm{~mm}^{3}$ ) was laid on the surface of the white paint and let interact with the paint layer for a variable time (from $5 \mathrm{~s}$ to $1.5 \mathrm{~min}$ ). Afterwards, the gel was removed and the swollen paint was gently cleaned off, performing a soft mechanical action using humid cotton swabs or a scalpel. 
Table 1

Complete set of samples used for the selective removal tests.

\begin{tabular}{|c|c|c|c|c|}
\hline & & \multicolumn{3}{|l|}{ Top layer } \\
\hline & & White (Vinyl) & White (Acrylic) & White (Alkyd) \\
\hline \multirow[t]{3}{*}{ Bottom layer } & Red (Vinyl) & $\mathrm{V} / \mathrm{V}$ & $\mathrm{A} / \mathrm{V}$ & $\mathrm{K} / \mathrm{V}$ \\
\hline & Green (Acrylic) & $\mathrm{V} / \mathrm{A}$ & $\mathrm{A} / \mathrm{A}$ & $\mathrm{K} / \mathrm{A}$ \\
\hline & Blue (Alkyd) & $\mathrm{V} / \mathrm{K}$ & $\mathrm{A} / \mathrm{K}$ & $\mathrm{K} / \mathrm{K}$ \\
\hline
\end{tabular}

$\mathrm{V}=$ vinyl-based paint; $\mathrm{A}$ = acrylic-based paint; $\mathrm{K}=$ alkyd-based paint

\subsection{In situ cleaning tests}

The tests performed on the real pieces of street art were performed with the NSF-loaded pHEMA/PVP gel. The gel was cut into small pieces (few square centimeters), which were laid on the surface of the undesired target paint for a variable time (up to $2 \mathrm{~min}$ ). After gel removal, the swollen paint was gently removed, performing a soft mechanical action using a humid cotton swab.

\subsection{Systems characteriziation}

\subsubsection{Small-angle $X$-ray scattering (SAXS)}

SAXS measurements were performed with a HECUS S3-MICRO SWAXS-camera, equipped with a Hecus System $32 \mathrm{D}$-point collimator (min divergence $0.4 \times 0.9 \mathrm{mrad}^{2}$ ) and two position sensitive detectors (PSD-50M) consisting of 1024 channels with a width of $54 \mu \mathrm{m}$. During the experiments, the $K_{\alpha}$ radiation $(\lambda=1.542 \AA$ ) emitted by a $\mathrm{Cu}$ anode from the Oxford $50 \mathrm{~W}$ microfocus source with customized FOX-3D single-bounce multilayer point focusing optics (Xenocs, Grenoble) was used, while the $K_{\beta}$ line was removed by a multilayer filter. The voltage is generated by the GeniX system (Xenocs, Grenoble). The sample-to-detector distance was $26.9 \mathrm{~cm}$. The volume between the sample and the detector was kept under vacuum during the measurements to minimize the scattering from the atmosphere. The camera was calibrated in the small-angle region using silver behenate $(d=58.38 \AA$ ). Scattering curves were obtained between 0.01 and $0.6 \AA^{-1} q$ range. The temperature control was set to $25^{\circ} \mathrm{C}$. Samples were measured in $1.5 \mathrm{~mm}$ thick quartz capillary tubes sealed with hot-melting glue. Scattering curves were corrected for the empty capillary contribution considering the relative transmission factors. Desmearing of the SAXS curves was not necessary due to the used focusing system.

\subsubsection{Attenuated total reflection - Fourier-transform infrared spectroscopy (ATR-FTIR)}

A FTIR spectrometer (Thermo Nicolet Nexus 870) equipped with a Golden Gate diamond cell was used to characterize the paints selected for this study. Data were collected with a MercuryCadmium-Telluride (MCT) detector with a sampling area of $150 \mu \mathrm{m}^{2}$. The spectra were obtained from 128 scans with $4 \mathrm{~cm}^{-1}$ of optical resolution.

\subsubsection{Micro-reflectance Fourier-transform infrared spectroscopy (microFTIR)}

Micro-reflectance FTIR analyses were performed on the samples used for the selective removal tests using the same Thermo Nicolet Nexus 870 infrared spectrometer equipped with a microscope for microanalysis. An MCT detector was used to collect the signal in the $4000-650 \mathrm{~cm}^{-1}$ range. A gilded surface was used to collect the background signal. The spectra were collected as single-beam files as the sum of 128 scans with a resolution of $4 \mathrm{~cm}^{-1}$. Then, they were divided by the background signal and transformed using the Kubelka-Munk algorithm, which is commonly used to display reflectance spectra [60].

\section{Results and discussion}

\subsection{Characterization of the selected paints}

For the present study, six professional grade artists' paints representative of the different types of binders have been selected, namely Flashe white and red vinyl-based paints (LeFranc \& Bourgeois), Heavy Body white and green acrylic-based paints (Liquitex), and Griffin white and blue alkyd-based paints (Winsor \& Newton).

Fig. 1 reports the ATR-FTIR spectra of the selected paints. The spectra are usually complicated due to the presence of signals from binder, pigment, extenders and other additives that often overlap. Table 2 shows the major paints features, including the chemical nature of binder, extenders and pigments.

Vinyl-based paints exhibit peaks at $2930 \mathrm{~cm}^{-1}$ and $2875 \mathrm{~cm}^{-1}$ due to the $\mathrm{CH}_{2}$ and $\mathrm{CH}_{3}$ asymmetric and symmetric stretching, while the $\mathrm{CO}$ carbonyl stretching is found at about $1735 \mathrm{~cm}^{-1}$. In the fingerprint region, peaks ascribed to the $\mathrm{CO}$ stretching are at $1234 \mathrm{~cm}^{-1}$ and $1024 \mathrm{~cm}^{-1}$, while the symmetric in-plane $\mathrm{CH}$ $[61,62]$ bending peak is at $1374 \mathrm{~cm}^{-1}$. To reduce the cost of raw material $[63,64]$ extenders or fillers, inorganic minerals whose refractive index approximately equals that of the binder, are usually added to the paints to replace the polymer or pigment volume. In both Flashe paints, calcite was used as an extender, as can be clearly detected from ATR-FTIR spectra, where the broad peak at about $1400 \mathrm{~cm}^{-1}$, and the sharp signals at $872 \mathrm{~cm}^{-1}$ and $712 \mathrm{~cm}^{-1}$ are due to the asymmetric stretching of carbonate group, to the asymmetric bending of the carbonate group, and to the $\mathrm{O}-\mathrm{C}-\mathrm{O}$ bending (in-plane deformation), respectively [64]. Titanium dioxide, which is the inorganic pigments of all the selected white paints, is usually assigned to a significant increase in the absorbance below $800 \mathrm{~cm}^{-1}$ in the ATR-FTIR spectra [65]. As indicated in the technical sheet, Flashe Oriental Red includes the organic pigment PR122, which belongs to the family of quinacridones, a class of lightfast red and violet pigments used for industrial coatings and artist's paints. Quinacridone pigments have extensive aromatic conjugation and absorbances due to primary or secondary amides, which overlap the signals of other organic components of the paints [63]. Conjugated carbonyl absorbance of the quinone is detected at $1672 \mathrm{~cm}^{-1}$ and the amide stretching are between 1600 and $1550 \mathrm{~cm}^{-1}$. In addition, signals related to the out-of-plane deformation of $\mathrm{CH}$ in aromatic rings are present at $760-740 \mathrm{~cm}^{-1}$ [66]. ATR-FTIR spectra of Heavy Body paints from Liquitex show an intense absorption at $1727 \mathrm{~cm}^{-1}$ (carbonyl stretching), less intense peaks at $2953 \mathrm{~cm}^{-1}$ and $2875 \mathrm{~cm}^{-1}(\mathrm{CH}$ stretching), and $\mathrm{CH}$ bending absorption at $1446 \mathrm{~cm}^{-1}$ and $1388 \mathrm{~cm}^{-1}$. These signals come from the acrylic binder [67]. In the green paint, signals at $1306 \mathrm{~cm}^{-1}, 1210 \mathrm{~cm}^{-1}, 1094 \mathrm{~cm}^{-1}$, $949 \mathrm{~cm}^{-1}$, and the doublet at 769 and $747 \mathrm{~cm}^{-1}$ can be ascribed to the phthalocyanine dye, i.e. Pigment Green 7 [66]. It is worth noting that in these acrylic paints extender or fillers are not detected by ATR-FTIR, and signals at $1343 \mathrm{~cm}^{-1}, 1114 \mathrm{~cm}^{-1}$, and $842 \mathrm{~cm}^{-1}$ are due to the presence of a nonionic polyethoxylated surfactant [68]. ATR-FTIR shows that the binder of Griffin paints from Winsor \& Newton is an alkyd-styrene copolymer. In fact, in 

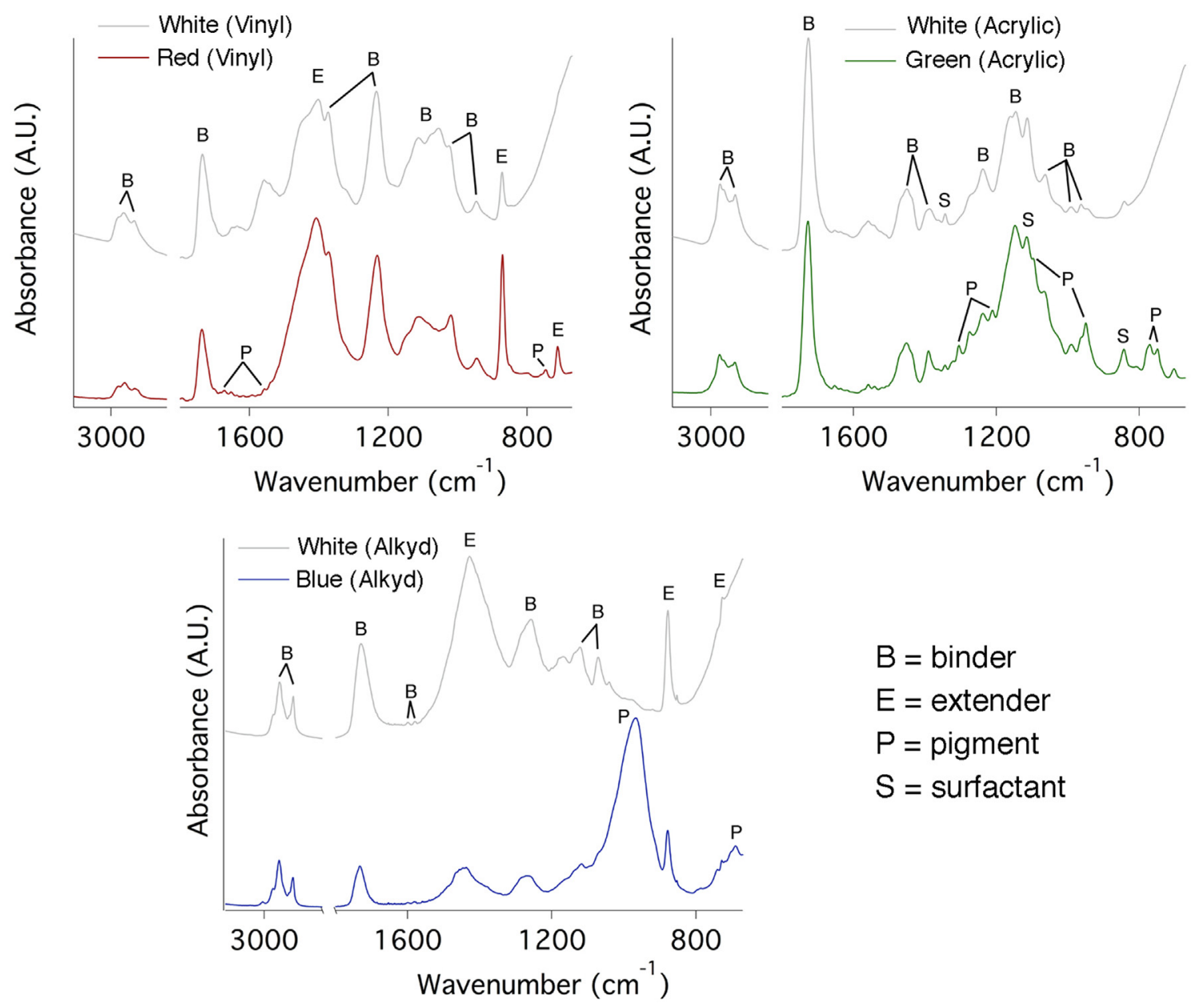

$$
\begin{aligned}
& B=\text { binder } \\
& E=\text { extender } \\
& P=\text { pigment } \\
& S=\text { surfactant }
\end{aligned}
$$

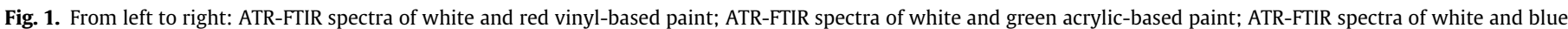

\begin{tabular}{|c|c|c|c|c|c|c|}
\hline \multirow[t]{2}{*}{ Commercial brand } & \multirow[t]{2}{*}{ Paint name } & \multirow[t]{2}{*}{ Sample name } & \multicolumn{4}{|c|}{ Paint components } \\
\hline & & & Binder & Extender & Pigment & Other \\
\hline \multirow[t]{2}{*}{ Flashe (LeFranc \& Bourgeois) } & Oriental red & Red (Vinyl) & \multirow[t]{2}{*}{ Vinyl } & \multirow[t]{2}{*}{ Calcite } & PR122 & \multirow[t]{2}{*}{-} \\
\hline & White 01 & White (Vinyl) & & & $\mathrm{TiO}_{2}$ & \\
\hline \multirow[t]{2}{*}{ Heavy Body (Liquitex) } & Phtalocyanine Green & Green (Acrylic) & \multirow[t]{2}{*}{ Acrylic } & \multirow[t]{2}{*}{-} & PG7 & \multirow[t]{2}{*}{ Nonionic surfactants (PEO type) } \\
\hline & Titanium White & White (Acrylic) & & & $\mathrm{TiO}_{2}$ & \\
\hline \multirow[t]{2}{*}{ Griffin (Winsor \& Newton) } & French Ultramarine & Blue (Alkyd) & \multirow[t]{2}{*}{ Alkyd } & \multirow[t]{2}{*}{ Dolomite } & Artificial ultramarine blue & \multirow[t]{2}{*}{-} \\
\hline & Titanium White & White (Alkyd) & & & $\mathrm{TiO}_{2}$ & \\
\hline
\end{tabular}
alkyd-based paint. (For interpretation of the references to colour in this figure legend, the reader is referred to the web version of this article.)

Table 2

Commercial names and composition of the six paints included in the study.

addition to the peaks belonging to alkyds $\left(\mathrm{CH}_{2}\right.$ and $\mathrm{CH}_{3}$ stretching at $2920 \mathrm{~cm}^{-1}$ and $2850 \mathrm{~cm}^{-1}$, CO carbonyl stretching at $1730 \mathrm{~cm}^{-1}$, and $\mathrm{CO}$ stretching at $1256 \mathrm{~cm}^{-1}$ ), some signals at about $1600 \mathrm{~cm}^{-1}$, which are commonly ascribed to the $\mathrm{C}=\mathrm{C}$ stretching in aromatic rings $[61,62,65]$, are shown in the spectra. The Blue sample (Alkyd), has a broad peak at $967 \mathrm{~cm}^{-1}$ and the less intense signals at $1068 \mathrm{~cm}^{-1}, 795 \mathrm{~cm}^{-1}$, and $680 \mathrm{~cm}^{-1}$ that are ascribable to the artificial ultramarine pigment, a sulfur-containing sodium-silicate [68], while signals at $1435 \mathrm{~cm}^{-1}, 878 \mathrm{~cm}^{-1}, 729 \mathrm{~cm}^{-1}$ are associated to the presence of dolomite $\left(\mathrm{MgCa}\left(\mathrm{CO}_{3}\right)_{2}\right)$ extender [69]. The dolomite extender is also found in the alkyd-based white pigment.

The solubility of the six paints was tested by immersing small samples of each paint dry film into $2 \mathrm{ml}$ of four alkyl carbonates (propylene carbonate, dimethyl carbonate, diethyl carbonate, dibutyl carbonate), and some solvents as water, ethanol, 2-butanol, ace- tone, xylene and cyclohexane, commonly used in conservation. These solvents were selected in order to cover a significant range of polarity and solving properties. The Teas diagram (Fig. 2A) shows that most of the selected solvents are close to or inside the solubility area of the synthetic polymers, indicating that they should be able to swell or solubilize the vinyl, acrylic and alkyd binders of the paints. Water is outside that area, as these polymers are hydrophobic and water-insoluble. However, solubility tests showed that none of the solvents was able to solubilize the paint films. On the other hand, most of the solvents, including water, were able to swell most of the paints, and the red dye (quinacridone) of the red vinyl-based paint was extracted from the film by all the solvents except water (see Fig. 2B). The interpretation of results of the solubility tests is not obvious since it is complicated by the fact that the paint films are formed from polymer 

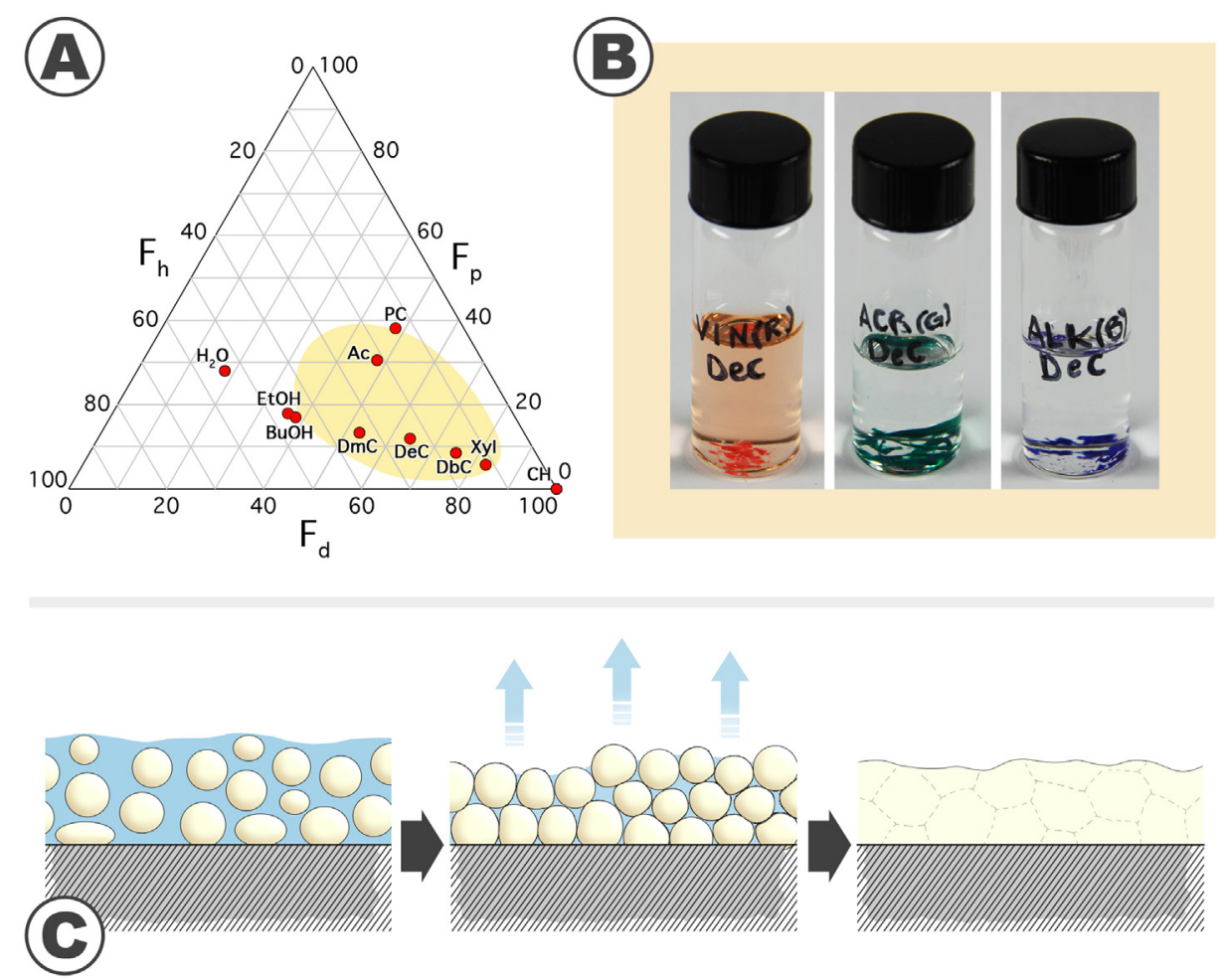

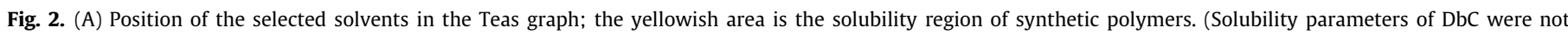

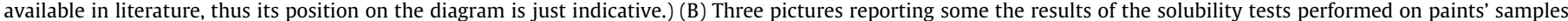

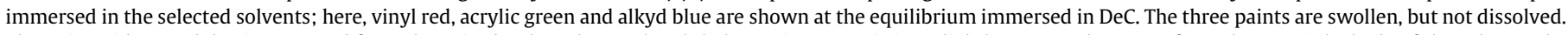

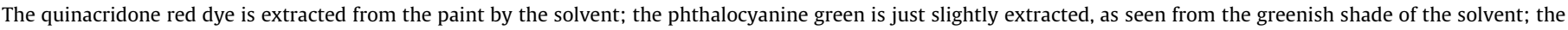

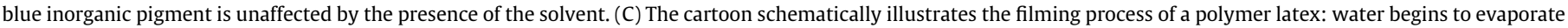

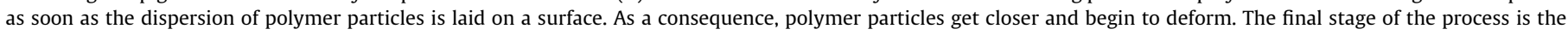

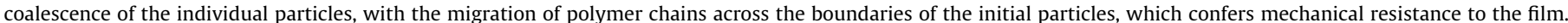

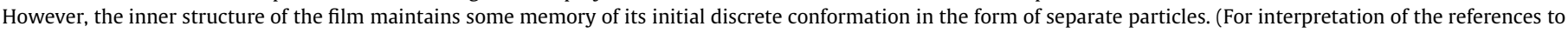
colour in this figure legend, the reader is referred to the web version of this article.)

latexes, i.e., aqueous emulsions, and not from polymer solutions. The filming process of polymer latexes is well-known and widely studied [70-73] and is sketched in Fig. 2C. Upon water evaporation, polymer particles become more concentrated and get closer. When the stress related to the drying process exceeds the elastic modulus of such particles, they begin to deform, producing a mechanically weak film because of the surfactant molecules embedded in the collapsed emulsion. In the final filming stage, the migration and consequent interpenetration of polymer chains belonging to different polymer particles provide mechanical strength to the film $[70,71]$. The final result of this process is a mechanically coherent polymer film (that includes pigments, fillers, surfactants, and other additives), which maintains a memory of the separated polymer particles. There are very few studies on the solubility of polymer latex films where polymer dissolution was observed [70]. The solvents selected for the present study were able to swell the polymer particles constituting the film but did not induce the complete polymer chain disentanglement needed to have polymer dissolution, as in the case of films obtained from polymer solutions. Due to this behavior, in order to disrupt and effectively remove polymer latex films, a mechanical action is needed.

Table 3 reports removability tests performed on single layers of paint applied on mortar tiles. It can be noticed that vinyl paints are more easily removable than acrylic, while alkyd are the hardest to be removed. The behavior of alkyd paints can be explained considering that alkyd polymers tend to crosslink over time, as the traditionally used drying oils, losing their initial solubility in most of organic solvents. Water is poorly effective on vinyl and acrylic paints, while it is completely ineffective on the alkyd ones. A highly non-polar hydrocarbon, such as cyclohexane, is even less effective than water on most of the paints. Finally, medium-to-high polar organic solvents, with the sole exception of PC and DbC (whose action is slightly less pronounced), are equally effective in removing vinyl and acrylic paints, while alkyd ones, as above reported, are more resistant to their removal.

\subsection{Formulation and characterization of the NSF}

The water miscibility of the four selected alkyl carbonates was investigated over the $10-80{ }^{\circ} \mathrm{C}$ temperature range. The sole complex behavior is the one of propylene carbonate [69], which has a significant miscibility gap at $10^{\circ} \mathrm{C}$, which decreases upon increasing the temperature, until complete mutual miscibility is reached for $\mathrm{T}>80^{\circ} \mathrm{C}$ (see Fig. 3 ).

In the observed range, linear alkyl carbonates have miscibility gaps that do not depend on temperature. In particular, diethyl carbonate, dibutyl carbonate, and water are completely immiscible, while dimethyl carbonate is miscible with water up to $10 \%(\mathrm{v} / \mathrm{v})$. In order to gather information about the action of a surfactant on systems' stability, the phase behavior of ternary mixtures, i.e., water/alkyl carbonate $/ \mathrm{C}_{12-14} \mathrm{E}_{9}$, was investigated. The results are reported in Fig. 4, which shows the investigated portion of the ternary phase diagrams. In the present case, in order to minimize the amount of possible non-volatile residues that would be left on the treated surfaces, the surfactant concentration was restricted to $20 \%$.

The phase behavior of the four alkyl carbonates when mixed with a water/surfactant solution shows a trend, which is clearly 
Table 3

Results of removal tests performed with neat unconfined solvents (application with cotton swabs).

\begin{tabular}{|c|c|c|c|c|c|c|}
\hline Solvent & Red (Vinyl) & White (Vinyl) & Green (Acrylic) & White (Acrylic) & Blue (Alkyd) & White (Alkyd) \\
\hline PC & Easy & Easy & Hard & Hard & No removal & No removal \\
\hline $\mathrm{DmC}$ & Easy & Easy & Easy & Easy & Hard & Hard \\
\hline DeC & Easy & Easy & Easy & Easy & Hard & Hard \\
\hline $\mathrm{DbC}$ & Easy & Easy & Hard & Hard & Hard & Hard \\
\hline $\mathrm{H}_{2} \mathrm{O}$ & Hard & Hard & Hard & Hard & No removal & No removal \\
\hline Ac & Easy & Easy & Easy & Easy & Hard & Hard \\
\hline EtOH & Easy & Easy & Easy & Easy & Hard & Hard \\
\hline $\mathrm{BuOH}$ & Easy & Easy & Easy & Easy & Hard & Hard \\
\hline Xyl & Easy & Easy & Easy & Easy & Hard & Hard \\
\hline $\mathrm{CH}$ & Hard & No removal & No removal & No removal & No removal & No removal \\
\hline
\end{tabular}

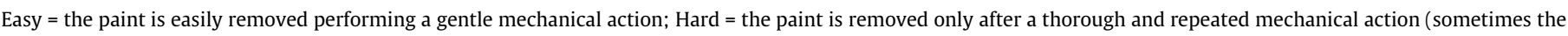
removal was incomplete); No removal = no significant paint removal was achieved.

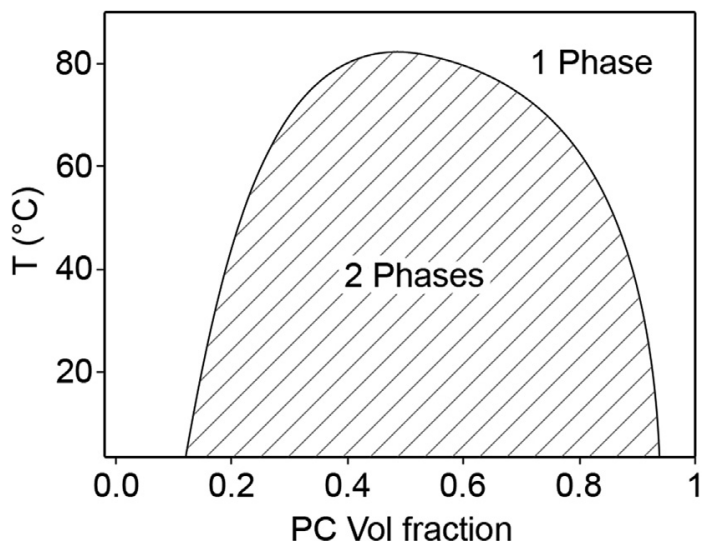

Fig. 3. Phase diagram of the $\mathrm{PC} / \mathrm{H}_{2} \mathrm{O}$ binary system. The temperature-dependent miscibility gap is visible in the graph. The samples investigated to build this phase diagram are reported in the supporting information file (Figure S1).

correlated to their water miscibility. The nonionic surfactant is capable of building-up stable monophasic systems (microemulsion) containing each of the selected alkyl carbonates as sketched in Fig. 4. Therefore, on the basis of solubility tests' results and phase behavior of alkyl carbonates, a new NSF was formulated as an alternative to the use of unconfined neat organic solvents and of less "green" NSFs previously employed in similar conservative contexts [58]. As reported in the Experimental Section, this new NSF is mainly composed by water, while PC and DeC are stabilized by an alcohol ethoxylate nonionic surfactant $\left(\mathrm{C}_{12-14} \mathrm{E}_{9}\right), \mathrm{BuOH}$, and an alkyl glycoside hydrotrope, AG6206. The effectiveness of DeC and DmC was similar for the removal of selected paints. However, $\mathrm{DeC}$ was chosen over $\mathrm{DmC}$, since it showed a broad range of possible conservation treatments; to mention one: the removal of aged pressure-sensitive tapes from drawings and paper with excellent results [74]. PC was chosen, despite its limited solving effectiveness in this case, with a twofold aim: i) due to its low volatility it prevents the softened paint from drying too quickly and ii) according to its ternary phase diagram, it should have been easily solubilized in the final NSF, with the final result of significantly increasing the amount of organic solvents in the formulation; $\mathrm{BuOH}$ acts as a cosurfactant. Finally, both the non-volatile chemicals of the NSF formulation, i.e. the nonionic surfactant and the alkyl glycoside hydrotrope, are eco-compatible, (bio)degradable compounds [75-81], making the system safe for the environment and virtually residue-free.

The NSF phase diagram was studied and four different formulations (points A-D in Fig. 5) were characterized by means of SAXS measurements to investigate their nanostructure. The study of size and shape of supramolecular aggregates, and the location of each component in the system is important since it is a necessary prerequisite to understand NSFs cleaning mechanism and to know whether a given cleaning fluid can be loaded into a gel.

After a preliminary screening of SAXS data, the A and C NSFs samples in the phase diagram (see Fig. 5) were modeled as polydisperse core-shell spheres, defined by two contrasts, i.e. bulk/shell and shell/core, and interacting according to a two-Yukawa (2Y) potential; NSFs B and D, on the other hand, were modeled as composed by non-interacting prolate core-shell ellipsoidal particles, thus again defined by a double contrast. The scattering length density (SLD) of bulk, shell and core, i.e., respectively, $\rho_{\text {bulk, }}, \rho_{\text {shell }}$ and $\rho_{\text {core, }}$ were calculated according to the SLD of each chemical included in the formulations, as reported in Table 4. For globular micelles of homogeneous scattering length density, the total scattered intensity $I(q)\left(\mathrm{cm}^{-1}\right)$, is given by $[82,83]$ :

$I(q)=N_{P} V_{P}^{2}(\Delta \rho)^{2} P(q) S(q)+\operatorname{bkg}_{\text {inc }}$

where $N_{p}$ is the number density of the scattering particles $\left(\mathrm{cm}^{-3}\right), V_{p}$ is the volume $\left(\mathrm{cm}^{3}\right), \Delta \rho$ is the contrast term $\left(\mathrm{cm}^{-2}\right), P$ $(q)$ is the form factor and $S(q)$ is the structure factor.

In the case of spherical core-shell aggregates, the particle scattering intensity is expressed as follows [84]:

$$
\begin{aligned}
I(q)= & \frac{\phi}{V_{P}}\left[\left(\rho_{\text {core }}-\rho_{\text {shell }}\right) \frac{3 V_{c} j\left(q r_{c}\right)}{q r_{c}}+\left(\rho_{\text {shell }}-\rho_{\text {bulk }}\right) \frac{3 V_{P} j\left(q r_{s}\right)}{q r_{s}}\right]^{2} S(q) \\
& +\operatorname{bkg}_{\text {inc }}
\end{aligned}
$$

where $j(x)$ is the first-order spherical Bessel function, and it is expressed as:

$j(x)=\frac{(\sin x-x \cos x)}{x^{2}}$

and where $\phi$ is the volume fraction of the micellar phase, $V_{c}$ is the core volume, $r_{c}$ is the core radius, $r_{s}=r_{c}+t$ ( $t$ is the shell thickness). Since this model takes into account a polydisperse core, which follows the Schultz distribution, the form factor calculated in equation (2) is normalized by the average particle volume:

$\langle V\rangle=\frac{4 \pi}{3}\left\langle r_{c}^{3}\right\rangle$

where:

$\left\langle r_{c}^{3}\right\rangle=\frac{(z+2)(z+3)}{(z+1)^{2}}\left\langle r_{c}\right\rangle$

and $z$ is the width parameter of the Schultz distribution[85]:

$z=\frac{1}{\left(\frac{\sigma}{\left\langle r_{c}\right\rangle}\right)^{2}}-1$ 

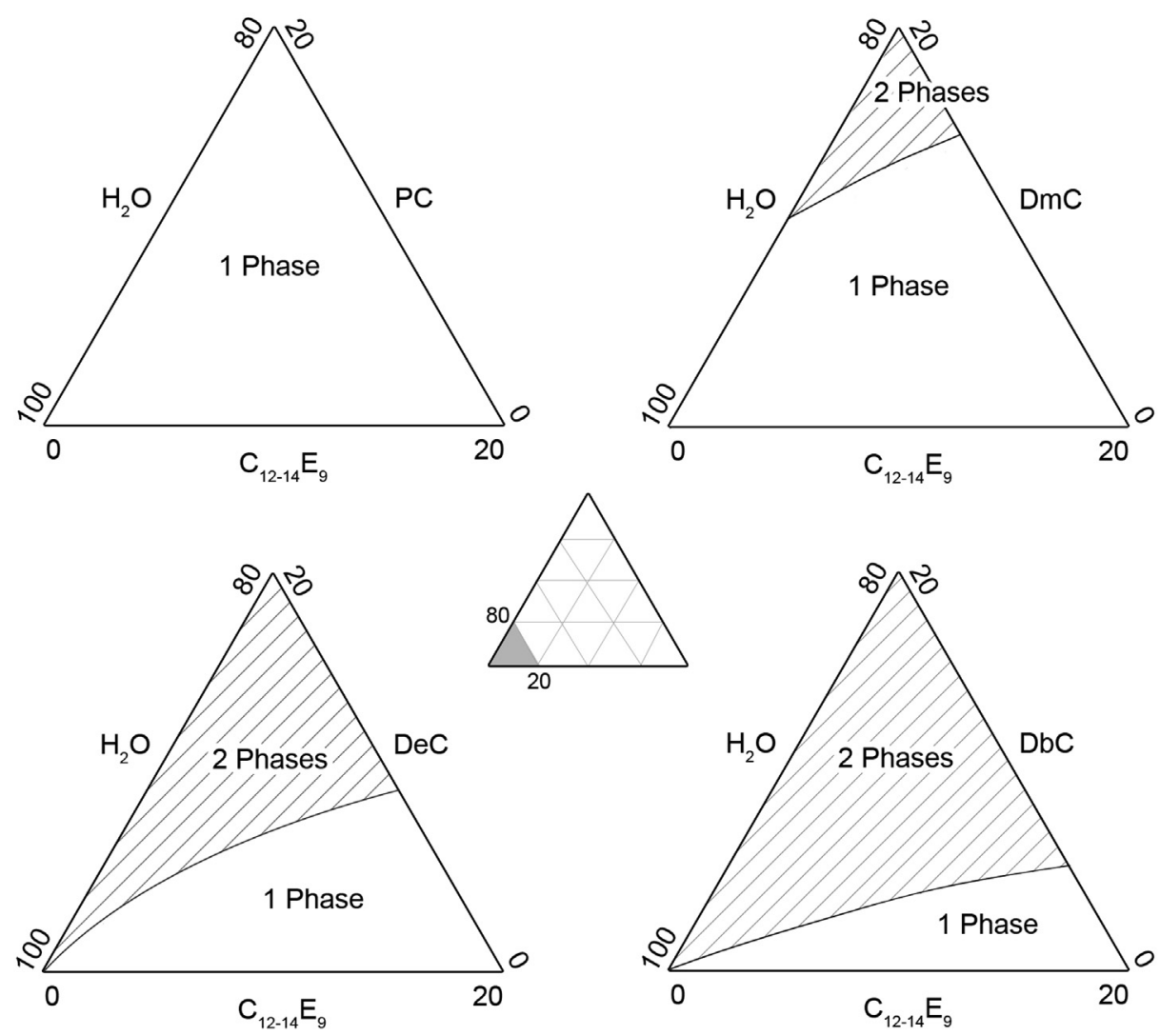

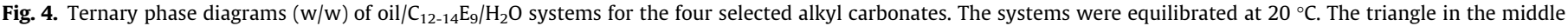

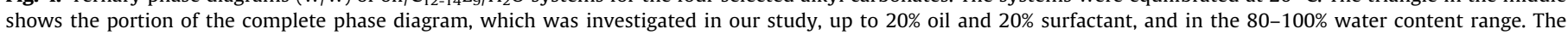
samples investigated to build this phase diagram are reported in the supporting information file (Figure S2).

being $\sigma^{2}$ the variance of the distribution. The polydispersity index (PDI), reported in Table 5 is defined as $\sigma /\left\langle r_{c}\right\rangle$ (see equation (6)) and its value is comprised between 0 and 1 . In the present study, similarly to a recent work [86] where we investigated NSFs based on similar alcohol ethoxylates, a 2Y structure factor [87] (often used to describe potentials such as DLVO-like or LennardJones-like ones [88-91] structure factor) was included, since the SAXS data could not be fitted with the sole form factor.

A $2 Y$ fluid is a system of particles interacting through a radial potential with the following form:

$\frac{V(r)}{K_{B} T}=\left\{\begin{array}{c}\infty,(0<r<1) \\ -K_{1} \frac{e^{-Z_{1}(r-1)}}{r}-K_{2} \frac{e^{-Z_{2}(r-1)}}{r},(r>1)\end{array}\right.$

where $r$ is normalized by the core diameter, $Z_{1}$ and $Z_{2}$ are the apparent charges inversely proportional to the interaction range, and $K_{1}$ and $K_{2}$ are scaling factors, which account for the intensity of each of the two combined Yukawa potentials. If $\mathrm{K}_{2}$ is negative, the first term in equation (7) is the attractive component, while the second is the repulsive one; thus, when $Z_{1}>Z_{2}$, as in the present case, according to fitting results, the interaction potential has the form of a short range attraction plus a long-range repulsive tail [89], which may adequately describe the behavior of nonionic micelles [92,93].

In the case of monodisperse non-interacting prolate ellipsoids, on the other hand, when modeling asymmetric micelles with a core-shell scattering length profile, $P(q)$ included in equation (1) is usually calculated as an orientationally-averaged normalized

form factor, $\bar{P}(q)$. The orientation-dependent form factor $F(\mathrm{q}, \mu)$, is defined as follows (where $\mu$ is the cosine between the direction of the symmetry axis of the ellipsoid and the $q$ vector):
$F(q, \mu)=f(\rho) \frac{3 j(u)}{u}+(1-f(\rho)) \frac{3 j(v)}{v}$

where $f(\rho)$ contains the contrast calculation, $j(x)$ is defined as in equation (3) and $u$ and $v$ are expressed as:

$u=q\left[\mu^{2} a^{2}+\left(1-\mu^{2}\right) b^{2}\right]^{1 / 2}$

$v=q\left[\mu^{2}\left(a+t_{a}\right)^{2}+\left(1-\mu^{2}\right)\left(b+t_{b}\right)^{2}\right]^{1 / 2}$

which define the geometrical shape of the micelles and where, $a, b, t_{a}$ and $t_{b}$ are the geometrical parameters of the ellipsoid, being the major semi-axis, the minor semi-axis, the shell thickness in the direction of $a$, and the shell thickness in the direction of $b$ respectively.

$\bar{P}(q)$ is then calculated as follows [94]:

$\bar{P}(q)=\int_{0}^{1}|F(q, \mu)|^{2} d \mu$

Fig. 6 reports the scattering profiles of the five analyzed NSFs together with their best fitting curves. The fitting parameters are reported in Table 5 .

A good fitting for systems B and D could be obtained only by modeling the micelles as prolate ellipsoids, indicating the presence of a sphere-to-rod transition close to the phase boundary. This is a very well known behavior typical of nonionic surfactants close to their cloud point. The result suggests that the cloud point of formulations $\mathrm{B}$ and $\mathrm{D}$ is slightly above $20^{\circ} \mathrm{C}$. On the other hand, systems $A$ and $C$ (the formulation selected for selective removal experiments) are composed of spherical micelles having a total radius of about 27-29 $\AA$, dispersed in a water/solvents mixture, where 


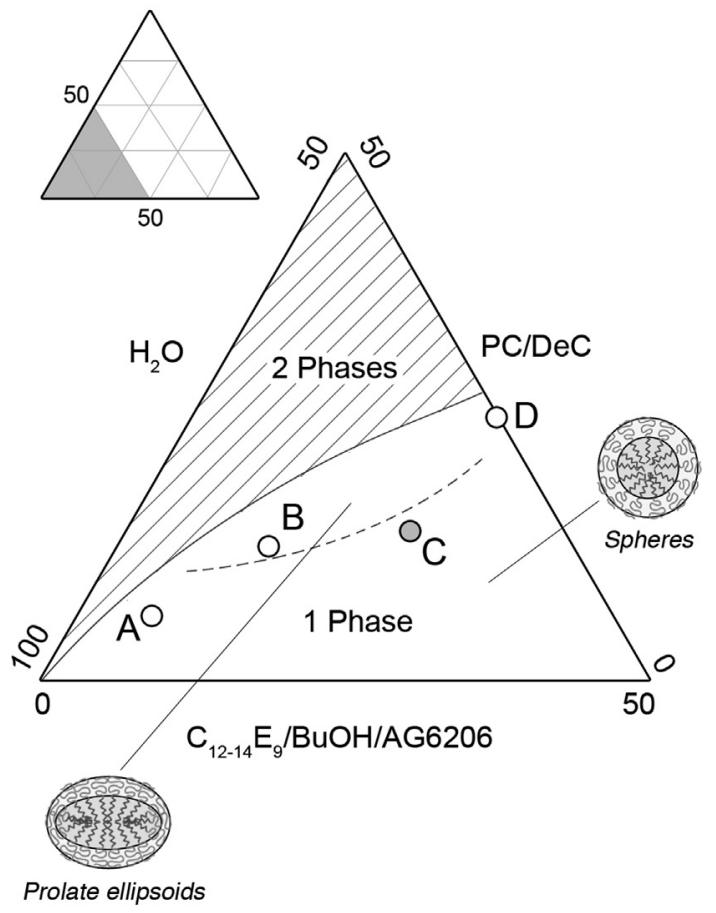

Fig. 5. Pseudo-ternary phase diagram $(w / w)$ for the six-components system proposed in this work. The samples were equilibrated at $20{ }^{\circ} \mathrm{C}$. The grey circle indicates the composition of the NSF selected for the cleaning tests. The dashed line indicates the boundary where a shape transition is observed for the aggregates: below the line micelles are globular, above (closer to the phase separation line) micelles tend to be more elongated. The samples investigated to build this phase diagram are reported in the supporting information file (Figure S3).

Table 4

SLD for X-ray scattering of the chemicals included in the NSFs.

\begin{tabular}{lll}
\hline Chemical formula/structure & Compound/molecular group & SLD $\left(10^{-6} \AA^{-2}\right)$ \\
\hline $\mathrm{CH}_{3}\left(\mathrm{CH}_{2}\right)_{11-13}\left(\mathrm{OCH}_{2} \mathrm{CH}_{2}\right)_{9} \mathrm{OH}$ & $\mathrm{C}_{12-14} \mathrm{E}_{9}{ }^{\mathrm{a}}$ & 9.5 \\
$\mathrm{CH}_{3}\left(\mathrm{CH}_{2}\right)_{11-13}{ }^{\mathrm{a}}$ & $\mathrm{C}_{12-14} \mathrm{E}_{9}$ apolar tail & 7.8 \\
$\mathrm{HO}\left(\mathrm{CH}_{2} \mathrm{CH}_{2} \mathrm{O}\right)_{9}$ & $\mathrm{C}_{12-14} \mathrm{E}_{9}$ polar head & 11.0 \\
$\mathrm{CH}_{3}\left(\mathrm{CH}_{2}\right)_{5} \mathrm{C}_{6} \mathrm{H}_{11} \mathrm{O}_{6}$ & AG6206 & 10.9 \\
$\mathrm{CH}_{3}\left(\mathrm{CH}_{2}\right)_{5}$ & AG6206 apolar tail & 7.4 \\
$\mathrm{C}_{6} \mathrm{H}_{11} \mathrm{O}_{6}{ }^{\mathrm{b}}$ & AG6206 polar head & 14.3 \\
$\mathrm{C}_{4} \mathrm{H}_{10} \mathrm{O}$ & $\mathrm{BuOH}$ & 7.8 \\
$\mathrm{C}_{4} \mathrm{H}_{6} \mathrm{O}_{3}$ & $\mathrm{PC}$ & 11 \\
$\mathrm{C}_{5} \mathrm{H}_{10} \mathrm{O}_{3}$ & DeC & 9
\end{tabular}

${ }^{a}$ For the SLD calculation, an average $C_{13}$ aliphatic chain was considered.

b The AG6206 polar head is a glucose molecule.

both $\mathrm{BuOH}$ and $\mathrm{PC}$, which are partly water-soluble, are partitioned between the continuous aqueous phase and the micellar phase.

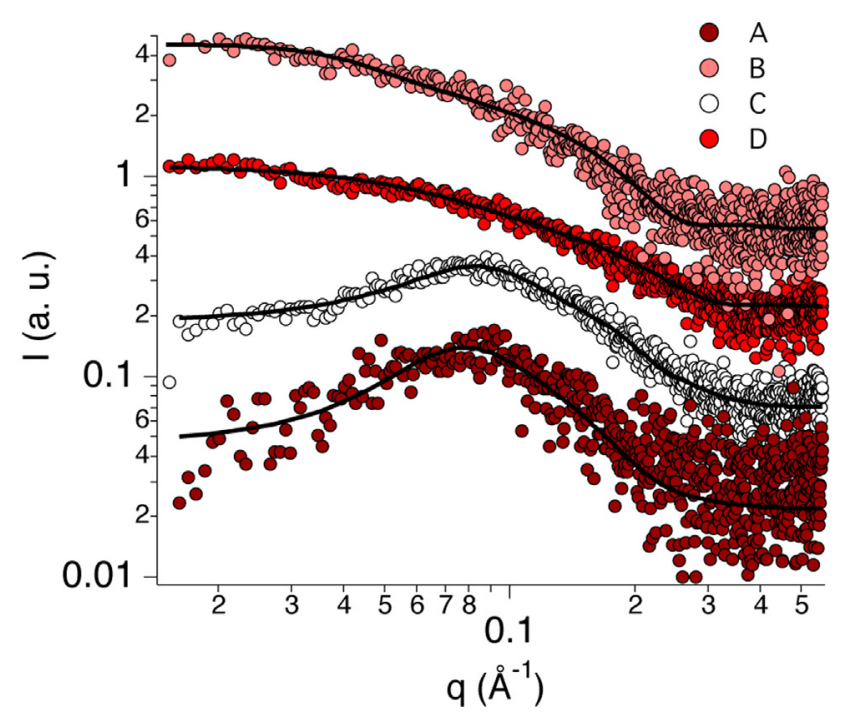

Fig. 6. SAXS profiles of the four NSF formulations analyzed (A-D), together with their best fitting curves (black solid lines). The curves were arbitrarily offset, for sake of clarity. Curve $C$ refers to the NSF formulation selected for the cleaning tests.

More in detail, about $70 \%(\mathrm{w} / \mathrm{w})$ of both solvents is dissolved in the bulk phase, while the remaining $30 \%$ is included in the micelles' polar shell. This result is consistent with other studies on PC and other water-miscible solvents included in NSFs [9597]. On the other hand, being DeC completely water-immiscible, it is fully located into the hydrophobic core of micelles. If we refer to system $\mathrm{A}$ and $\mathrm{C}$, the core radius, $r \approx 16 \AA$, is consistent with the molecular size of $\mathrm{C}_{12-14} \mathrm{E}_{9}$, whose aliphatic tail should be, according to Tanford [98], about $18 \AA$ A long, with a polydispersity index of $0.2-0.3$, which is common for microemulsions. It can be noticed that the shell thickness is sensibly reduced along the phase boundary from system B to D. This is consistent with an increased dehydration of polar heads of the alcohol ethoxylate surfactant in the $\mathrm{D}$ formulation, or, in other words, with the fact that the D sample is closer to its cloud point and to the phase boundary (see Fig. 5).

Finally, system $\mathrm{C}$ was selected as the formulation to be used for cleaning tests. This formulation was chosen not too close to the phase boundary, in order to optimize for practical applications the amount of organic solvents and the cloud point value.

It has been demonstrated that NSFs loaded in chemical hydrogels possess enhanced cleaning capacities [37,39,41]. The NSF studied in this paper was loaded within a pHEMA/PVP hydrogel and used to perform a systematic series of selective removal tests on two paint layers deposited over mortar tiles.

Table 5

Fitting parameters for the analyzed NSF formulations. System $C$ is the formulation selected for the cleaning tests.

\begin{tabular}{lllll}
\hline Parameter & $\mathrm{A}$ & $\mathrm{B}$ & $\mathrm{C}$ & $\mathrm{D}$ \\
\hline$r_{c}(\AA)$ & 15.4 & - & 16.8 & - \\
$t(\AA)$ & 12.2 & - & 12.5 & - \\
$a(\AA)$ & - & 86.5 & - & 47.2 \\
$b(\AA)$ & - & 14.4 & - & 11.7 \\
$t_{a}(\AA)$ & - & 30.5 & - & 5.0 \\
$t_{b}(\AA)$ & - & 11.2 & - & 8.5 \\
$\mathrm{PDI}$ & 0.3 & - & 0.4 & - \\
$\mathrm{K}_{1}$ & 1.9 & - & 2.0 & - \\
$\mathrm{Z}_{1}$ & 37.3 & - & 21.0 & - \\
$\mathrm{K}_{2}$ & -2.3 & - & -1.5 & - \\
$\mathrm{Z}_{2}$ & 3.5 & - & 3.5 & - \\
\hline
\end{tabular}




\subsection{Laboratory selective removal tests}

As a preliminary test, the effect of both DeC and the selected NSF was tested using cotton swabs soaked with the cleaning fluids. As expected, no selective removal was obtained, neither with the neat organic solvent nor with the NSF, due to the poor control on the penetration and the spreading of the cleaning liquid on the treated materials. The loading of the NSF into a highly retentive easily handleable and residue-free chemical hydrogel allowed a better control and improved the effectiveness in the selective removal of the over-paintings. Fig. 7 reports the complete set of samples with the cleaning results. Several small squares are visible on the tiles, where the white paint was removed to a certain extent. It was found that repeated short applications of the NSFloaded gel are more effective than a longer single application. After each application of the gel, the softened white paint was removed by means of a gentle mechanical action performed with a humid cotton swab or a scalpel. The proposed methodology is effective in the selective removal of the white paint from the colored layers, without significant damages to the underlying paint films. As observed during solubility tests, the vinyl and the acrylic paints were quite easily removed, while the alkyd white was just partly removed only after a more intense mechanical action. The most interesting cases are the samples $\mathrm{V} / \mathrm{V}, \mathrm{A} / \mathrm{A}$ and $\mathrm{K} / \mathrm{K}$ where the paint layer to be removed has the same chemical nature of the paint layer to be preserved. The removal of the white paint was very good with the alkyd blue specimens, while the white was slightly contaminated by the underneath pigments when organic quinacridone and phthalocyanine dyes (vinyl red and acrylic green, respectively) are present.

These mockups were further characterized by means of highmagnification pictures and micro-reflectance FTIR analyses. Fig. 8 shows sample $\mathrm{V} / \mathrm{V}$ (the other samples are not reported for sake of conciseness). FT-IR analyses and reported micrographs confirm that the top vinyl white paint layer was completely removed, while the vinyl red paint layer underneath was not significantly damaged or altered. In particular, from FTIR spectra reported in Fig. 8, it can be noticed that reflectance profiles of the treated area and of the red paint are similar, while the spectrum of the white paint is significantly different from the other paints, meaning that residues of white paint are either absent or undetectable within the instrumental sensitivity.

\subsection{In situ cleaning tests}

Finally, after the mock-up selective removal tests, the proposed methodology was assessed in situ on some real pieces of street art, which were vandalized with black writings and tags. The figurative painting reported in Fig. 9 was a perfect case study to test the cleaning methodology here proposed. The same NSF-loaded hydrogel used in laboratory tests was used to selectively act on the undesired black paint, which was successfully removed without affecting the underlying paint layers.

Fig. 9A shows the whole graffiti painting, realized with commercial spray-can paints. The tags' black paint and the original greyish paint were analyzed through ATR-FTIR and microreflectance; the obtained spectra (not reported here for sake of conciseness) showed that both these paints are based on acrylic binders. The NSF-loaded hydrogel was able to quickly and selectively remove both of them. The inset reported in Fig. 9B shows a close-up of the area where selective removal tests were carried out. Fig. 9C-F were taken during the cleaning and show the application of the gel and the subsequent black paint removal with humid cotton swabs. Finally, Fig. 9G show the eyes region of the figure, with the cleaned area (approx. $6 \mathrm{~cm}^{2}$ ) clearly visible just above the white circle.
Fig. 10A and B show additional tests, where black writings, probably made with felt-tip permanent markers, were completely removed from street art pieces. From top to bottom, the reported pictures show the gradual removal of the writings, performed with the repeated application of NSF-loaded highly retentive hydrogels followed by some mechanical action with humid cotton swabs, until complete removal of the vandalism.

These tests represent a reliable assessment of the applicability of this cleaning approach to real street art.

\section{Conclusions}

Selective removal of over-paintings and vandalism is emerging as a novel and interesting issue in conservation of cultural heritage. Graffiti on street art is probably the most remarkable and difficult example of conservation involving the selective removal of an unwanted paint layer from a chemically similar paint layer that is meant to be preserved. Nowadays traditional methodologies (chemicalor physical) do not offer satisfactory solutions to this important conservation issue. Here we proposed the use of oil-in-water nanostructured fluid (NSF) loaded in poly (hydroxyethyl methacrylate)/poly(vinyl pyrrolidone) (pHEMA/ PVP) highly retentive hydrogels to perform finely controlled and selective removal of over-paintings. We selected six paints including different binder classes, i.e., vinyl, acrylic and alkyd polymers. These paints were characterized by means of attenuated total reflection Fourier transform infrared spectroscopy (ATR-FTIR) and their composition was unveiled in terms of binders, pigment and fillers (where detectable). The same paints were then subjected to solubility tests both by immersion in neat solvents and via mechanical action performed with cotton swabs soaked with the same solvents. It was found that vinyl and acrylic paints were quite easily removed by a wide range of medium-to-high polar solvents, while alkyd paints were hardly removable without mechanical action. Once the most suitable solvents were selected, a "green", low-toxicity and eco-compatible NSF was formulated, as a result of a thorough study on alkyl carbonates' phase diagrams, which included a nonionic surfactant, a medium chain length alcohol, an alkyl glycoside, and two alkyl carbonates in a water $(>60 \% \mathrm{w} / \mathrm{w})$ environment. This system represents a valid alternative to the use of unconfined neat organic solvents, and of less "green" NSFs previously employed in similar conservative contexts [58]. The nanostructure of this system was characterized by means of smallangle X-ray scattering measurements. It was found that the dispersed phase is composed by fairly polydisperse globular micellar aggregates having a radius of about $3 \mathrm{~nm}$ and surrounded by a continuous water/propylene carbonate/2-butanol mixture as bulk phase. This system was then loaded in a pHEMA/PVP semi-interpenetrated hydrogel, which was used to perform systematic selective removal tests on mortar tiles prepared with superimposed paint layers taking into account all the possible binders' combinations. We showed that the proposed methodology is effective for the selective removal of over-paintings. In particular, it was possible to achieve a satisfactory removal in the most interesting cases of vinyl-on-vinyl and acrylic-onacrylic samples, while alkyd-on-alkyd specimens were partly resistant to the removal. This represents a substantial improvement over previous formulations used for the same purpose [58], and a major advancement with respect to the existing methodologies available to conservators [3-13,26-28]. FTIR measurements on the treated areas confirmed that the overlying paint was almost completely removed without altering the paint layer underneath. Finally, the proposed methodology and cleaning system were assessed in the selective removal of black tags 

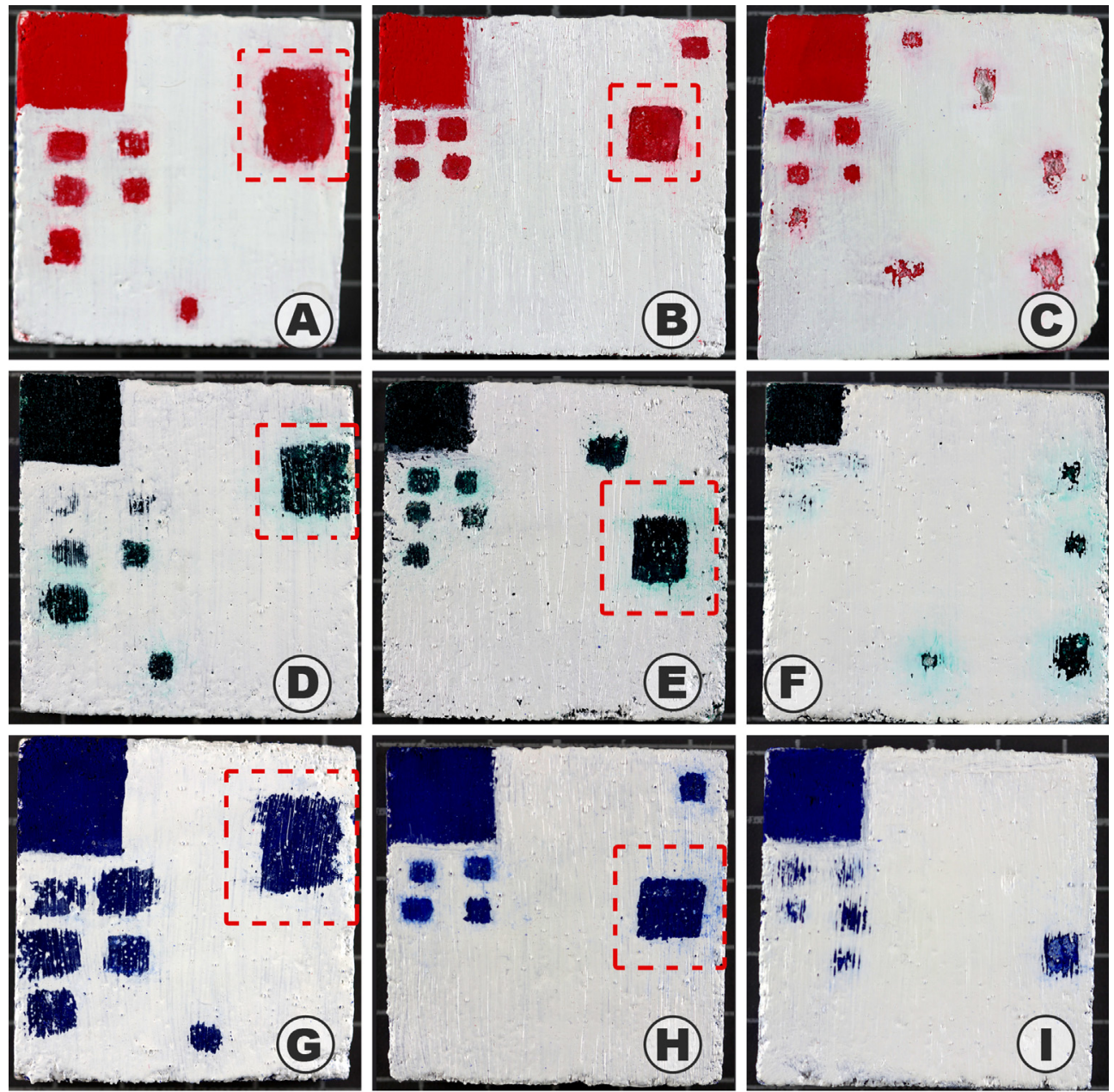

$4 \mathrm{~cm}$

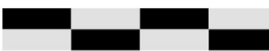

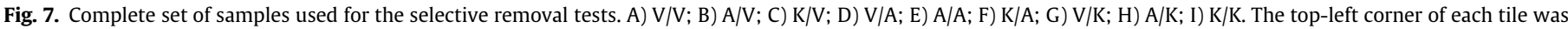

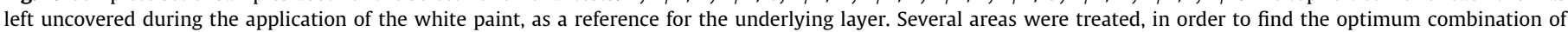

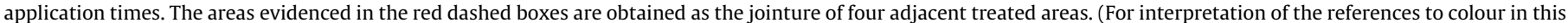
figure legend, the reader is referred to the web version of this article.)

from real pieces of street art, with very good results. Future perspectives include the use of the developed eco-compatible NFS loaded in different highly retentive gels, such as twin-chain polymer hydrogels, whose adaptability to rough surfaces may represent a key feature for the improved removal of overpaintings from rough, clotted and three-dimensionally textured substrates. In conclusion, a water-based low-toxicity and ecocompatible system was successfully used to contribute to the solution of the growing issue of selective removal of overpaintings and street art/graffiti vandalism, offering a new important tool to Conservation Science.

\section{Authors contribution}

PB and RG conceptualized the study; MB, GP carried out the experiments; $\mathrm{MB}$ and $\mathrm{PR}$ performed the phase diagram; MB performed the SAXS analysis; GP and MB performed the physicochemical characterization and the cleaning tests on graffiti. TO, $\mathrm{PB}, \mathrm{MB}$ RG and GP discussed the data analysis. All authors contributed to the present text.

\section{Declaration of Competing Interest}

The authors declare that they have no known competing financial interests or personal relationships that could have appeared to influence the work reported in this paper.

\section{Acknowledgements}

Krister Holmberg, Romain Bordes, Chalmers University of Technology (Gotheborg, Sweden) and Michael Persson Akzo Nobel are kindly acknowledged for the helpful discussion and for providing us with the AG 6206 alkyl glycoside. Felipe Hidetomo Sekine, from Nikkol company is acknowledged for providing the $\mathrm{C}_{12-14} \mathrm{E}_{9}$ nonionic surfactant and for the helpful discussion. Massimo Ceccato is acknowledged for providing dibutyl carbonate.

MUR (PRIN 2017249YEF) and CSGI are acknowledged for funding this work. 


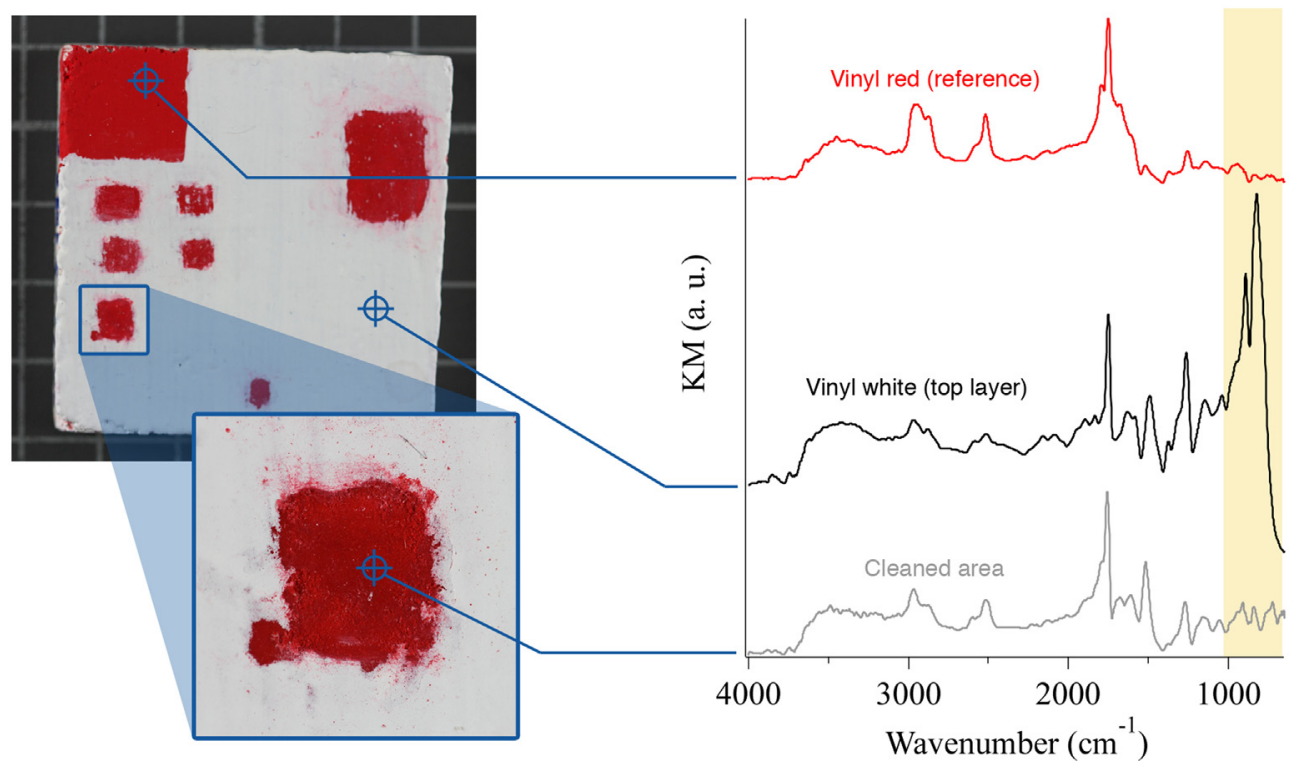

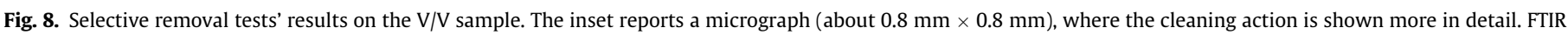

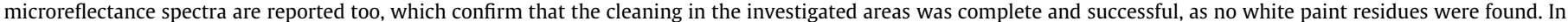

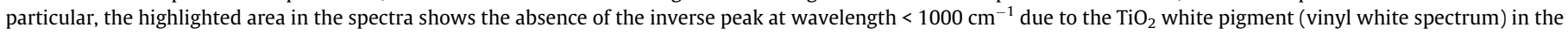
cleaned area.
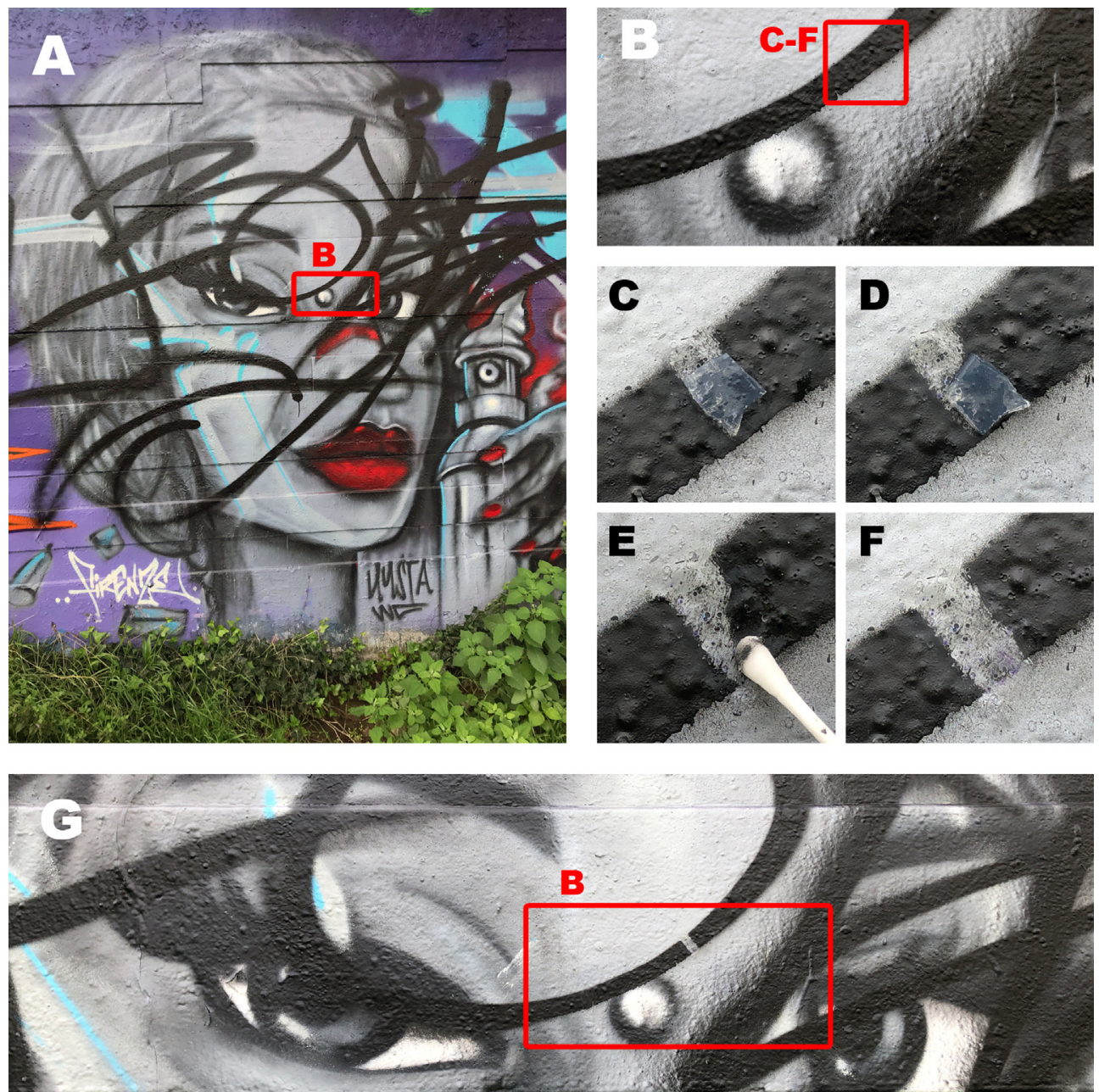

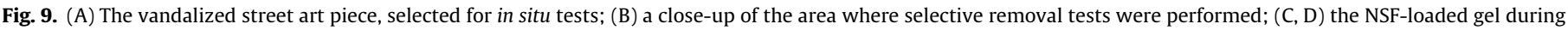
the application; (E) mechanical action performed with a humid cotton swab on the swollen overpainting; (F, G) final result of the cleaning. 

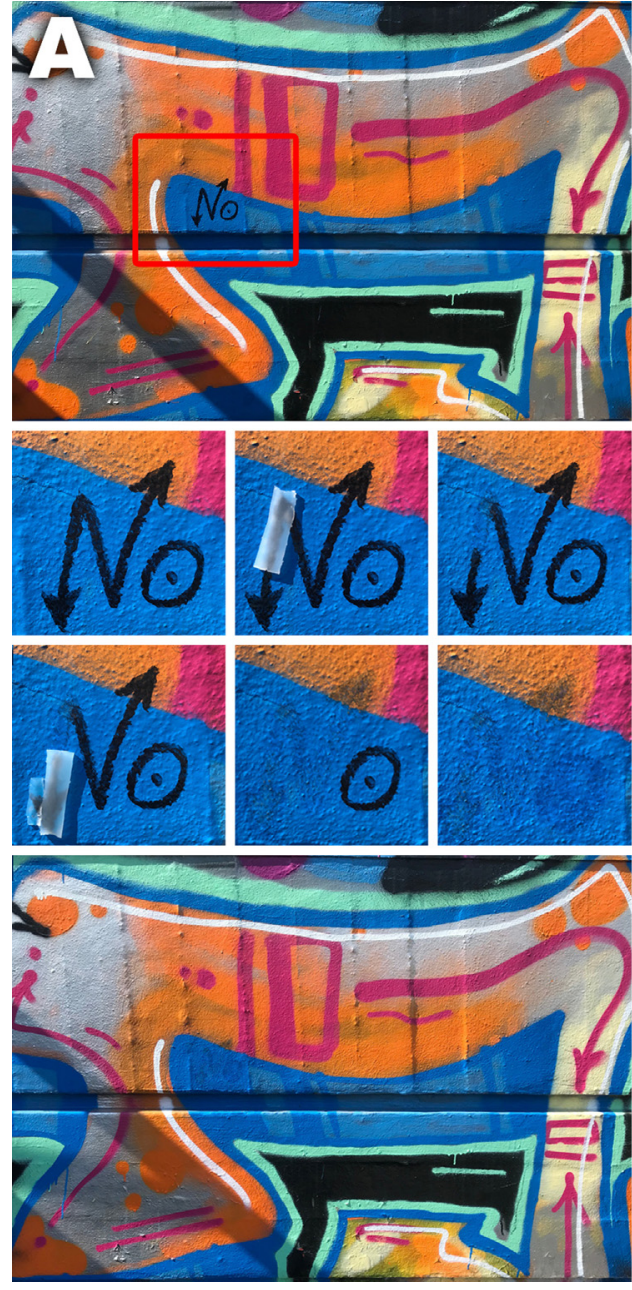
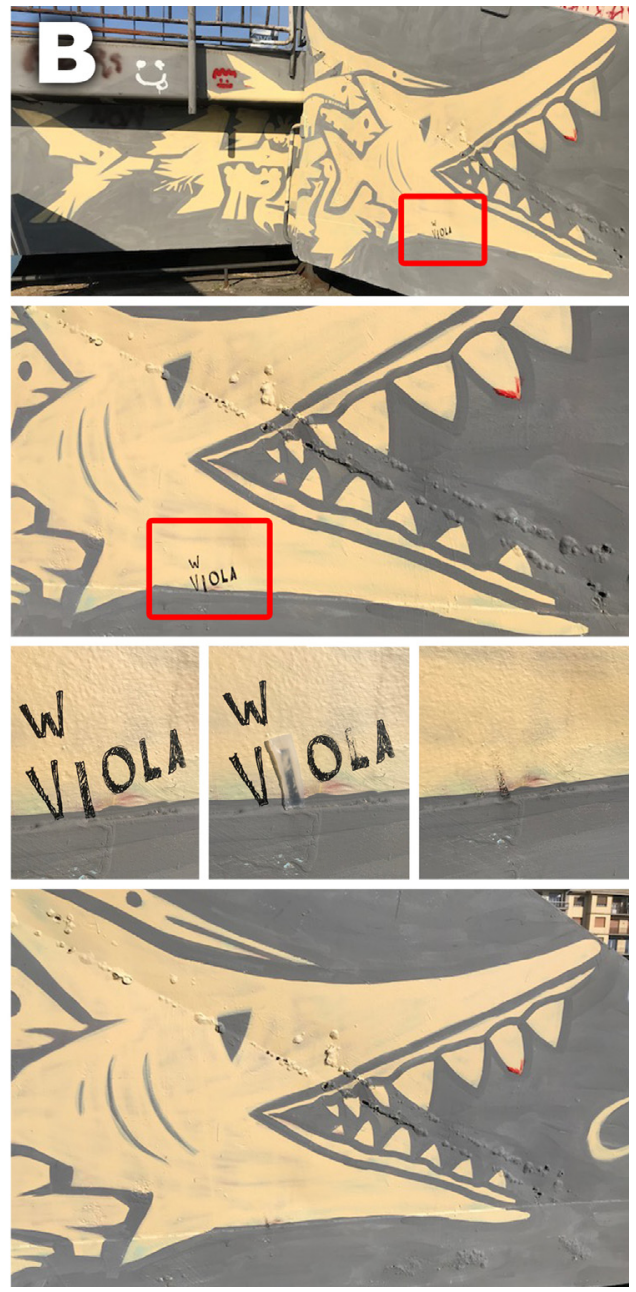

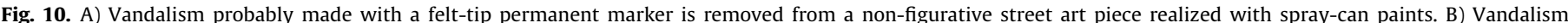

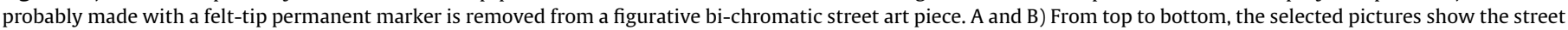

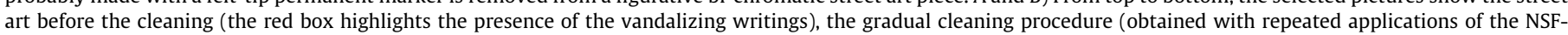

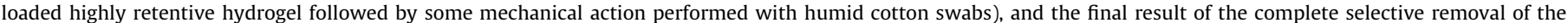
vandalism. (For interpretation of the references to colour in this figure legend, the reader is referred to the web version of this article.)

\section{Appendix A. Supplementary material}

Supplementary data to this article can be found online at https://doi.org/10.1016/j.jcis.2021.03.054.

\section{References}

[1] Eduardo Kobra website, n.d. Available from: <https://www.eduardokobra.com/

[2] Banksy website, n.d. Available from: <https://www.banksy.co.uk/>

[3] P. Sanmartín, F. Cappitelli, R. Mitchell, Current methods of graffiti removal: a review, Constr. Build. Mater. 71 (2014) 363-374, https://doi.org/10.1016/ j.conbuildmat.2014.08.093.

[4] S. Chapman, Laser technology for graffiti removal, J. Cult. Herit. 1 (Supplement 1) (2000) S75-S78, https://doi.org/10.1016/S1296-2074(00)00153-9.

[5] P. Ortiz, V. Antúnez, R. Ortiz, J.M. Martín, M.A. Gómez, A.R. Hortal, B. MartínezHaya, Comparative study of pulsed laser cleaning applied to weathered marble surfaces, Appl. Surf. Sci. 283 (2013) 193-201, https://doi.org/10.1016/j. apsusc.2013.06.081.

[6] M. Carvalhão, A. Dionísio, Evaluation of mechanical soft-abrasive blasting and chemical cleaning methods on alkyd-paint graffiti made on calcareous stones, J. Cult. Herit. 16 (2015) 579-590, https://doi.org/10.1016/j.culher.2014.10.004.

[7] S. Samolik, M. Walczak, M. Plotek, A. Sarzynski, I. Pluska, J. Marczak, Investigation into the removal of graffiti on mineral supports: Comparison of nano-second Nd:YAG laser cleaning with traditional mechanical and chemical methods, Stud. Conserv. 60 (2015) S58-S64, https://doi.org/10.1179/ $0039363015 Z .000000000208$.

[8] J.S. Pozo-Antonio, T. Rivas, M.P. Fiorucci, A.J. López, A. Ramil, Effectiveness and harmfulness evaluation of graffiti cleaning by mechanical, chemical and laser procedures on granite, Microchem. J. 125 (2016) 1-9, https://doi.org/10.1016/j. microc.2015.10.040.

[9] F. Brygo, Ch. Dutouquet, F. Le Guern, R. Oltra, A. Semerok, J.M. Weulersse, Laser fluence, repetition rate and pulse duration effects on paint ablation, Appl. Surf. Sci. 252 (2006) 2131-2138, https://doi.org/10.1016/j.apsusc.2005.02.143.

[10] A. Costela, I. Garćía-Moreno, C. Gómez, O. Caballero, R. Sastre, Cleaning graffitis on urban buildings by use of second and third harmonic wavelength of a Nd: YAG laser: a comparative study, Appl. Surf. Sci. 207 (2003) 86-99, https://doi. org/10.1016/S0169-4332(02)01241-2.

[11] C. Gómez, A. Costela, I. García-Moreno, R. Sastre, Comparative study between IR and UV laser radiation applied to the removal of graffitis on urban buildings, Appl. Surf. Sci. 252 (2006) 2782-2793, https://doi.org/10.1016/j. apsusc.2005.04.051.

[12] J. Penide, F. Quintero, A. Riveiro, A. Sánchez-Castillo, R. Comesaña, V. del, Keeping historical with lasers. How to remove the graffiti without damaging the underlying material. (Application report), Ind. Laser Solut. (2013) 18-21.

[13] T. Rivas, S. Pozo, M.P. Fiorucci, A.J. López, A. Ramil, Nd:YVO4 laser removal of graffiti from granite. Influence of paint and rock properties on cleaning efficacy, Appl. Surf. Sci. 263 (2012) 563-572, https://doi.org/10.1016/j. apsusc.2012.09.110.

[14] D. Barca, C.M. Belfiore, G.M. Crisci, M.F.L. Russa, A. Pezzino, S.A. Ruffolo, Application of laser ablation ICP-MS and traditional techniques to the study of black crusts on building stones: a new methodological approach, Environ. Sci. Pollut. Res. 17 (2010) 1433-1447, https://doi.org/10.1007/s11356-010-03298.

[15] E. Gioventù, P.F. Lorenzi, F. Villa, C. Sorlini, M. Rizzi, A. Cagnini, A. Griffo, F Cappitelli, Comparing the bioremoval of black crusts on colored artistic lithotypes of the Cathedral of Florence with chemical and laser treatment, Int. Biodeterior. Biodegrad. 65 (2011) 832-839, https://doi.org/10.1016/j. ibiod.2011.06.002. 
[16] G. Marakis, P. Pouli, V. Zafiropulos, P. Maravelaki-Kalaitzaki, Comparative study on the application of the 1st and the 3rd harmonic of a Q-switched Nd: YAG laser system to clean black encrustation on marble, J. Cult. Herit. 4 (Supplement 1) (2003) 83-91, https://doi.org/10.1016/S1296-2074(02)012086.

[17] S.S. Potgieter-Vermaak, R.H.M. Godoi, R.V. Grieken, J.H. Potgieter, M. Oujja, M. Castillejo, Micro-structural characterization of black crust and laser cleaning of building stones by micro-Raman and SEM techniques, Spectrochim. Acta. A. Mol. Biomol. Spectrosc. 61 (2005) 2460-2467, https://doi.org/10.1016/j. saa.2004.09.010.

[18] M.I. Cooper, D.C. Emmony, J. Larson, Characterization of laser cleaning of limestone, Opt. Laser Technol. 27 (1995) 69-73, https://doi.org/10.1016/00303992(95)93962-Q.

[19] I. Gobernado-Mitre, A.C. Prieto, V. Zafiropulos, Y. Spetsidou, C. Fotakis, On-line monitoring of laser cleaning of limestone by laser-induced breakdown spectroscopy and laser-induced fluorescence, Appl. Spectrosc. 51 (1997) 1125-1129.

[20] P.V. Maravelaki, V. Zafiropulos, V. Kilikoglou, M. Kalaitzaki, C. Fotakis, Laserinduced breakdown spectroscopy as a diagnostic technique for the laser cleaning of marble, Spectrochim. Acta Part B At. Spectrosc. 52 (1997) 41-53, https://doi.org/10.1016/S0584-8547(96)01573-X.

[21] G. Buccolieri, V. Nassisi, L. Torrisi, A. Buccolieri, A. Castellano, M.D. Giulio, E. Giuffreda, D.D. Side, L. Velardi, Analysis of selective laser cleaning of patina on bronze coins, J. Phys. Conf. Ser. 508 (2014), https://doi.org/10.1088/17426596/508/1/012032 012032.

[22] S. Acquaviva, E. D’Anna, M.L. De Giorgi, A.D. Patria, L. Pezzati, D. Pasca, L. Vicari, F. Bloisi, V. Califano, Laser cleaning of gilded wood: a comparative study of colour variations induced by irradiation at different wavelengths, Appl. Surf. Sci. 253 (2007) 7715-7718, https://doi.org/10.1016/j.apsusc.2007.02.178.

[23] D. Ciofini, I. Osticioli, S. Micheli, L. Montalbano, S. Siano, Laser removal of mold and foxing stains from paper artifacts: preliminary investigation, 2013, pp. 906512-906512-11. doi: 10.1117/12.2052820.

[24] T. Ersoy Cetin, Uguryol Mehmet, Gurcan Mavili, Selcuk Akturk, Cetin Yaman, High-selectivity cleaning of historical paper samples with sizing through femtosecond laser ablation, Proc. SPIE- Int. Soc. Opt. Eng. 9527 (2015) 952703.

[25] V.E. Selva Bonino, Dall'olio all'acrilico, dall'impressionismo all'arte contemporanea: studi, ricerche, indagini scientifiche ed interventi conservativi: Atti del congresso, Milano 13-14 novembre 2015: VII congresso internazionale Colore e Conservazione, Il Prato, Saonara, 2016.

[26] I. Apostol, V. Damian, F. Garoi, I. Iordache, M. Bojan, D. Apostol, A. Armaselu, P. J. Morais, D. Postolache, I. Darida, Controlled removal of overpainting and painting layers under the action of UV laser radiation, Opt. Spectrosc. 111 (2011) 287, https://doi.org/10.1134/S0030400X11080054.

[27] D. Ciofini, I. Osticioli, A. Pavia, S. Siano, Removal of overpaintings from easel paintings using LQS Nd:YAG laser, Appl. Phys. A. 117 (2014) 341-346, https:// doi.org/10.1007/s00339-014-8318-2.

[28] S. Siano, I. Osticioli, A. Pavia, D. Ciofini, Overpaint removal from easel paintings using an LQS Nd:YAG laser: the first validation study, Stud. Conserv. 60 (2015) S49-S57, https://doi.org/10.1179/0039363015Z.000000000207.

[29] M. Baglioni, G. Poggi, G. Ciolli, E. Fratini, R. Giorgi, P. Baglioni, A triton X-100based microemulsion for the removal of hydrophobic materials from works of art: SAXS characterization and application, Materials 11 (2018) 1144, https:// doi.org/10.3390/ma11071144.

[30] M. Baglioni, T. Guaragnone, R. Mastrangelo, F.H. Sekine, T. Ogura, P. Baglioni, Nonionic surfactants for the cleaning of works of art: insights on acrylic polymer films dewetting and artificial soil removal, ACS Appl. Mater. Interfaces. 12 (2020) 26704-26716, https://doi.org/10.1021/acsami.0c06425.

[31] K. Segel, I. Brajer, M. Taube, C. Martin de Fonjaudran, M. Baglioni, D. Chelazzi, R. Giorgi, P. Baglioni, Removing ingrained soiling from medieval lime-based wall paintings using nanorestore Gel ${ }^{\circledR}$ Peggy 6 in combination with aqueous cleaning liquids, Stud. Conserv. (2020) 1-8, https://doi.org/10.1080/ 00393630.2020 .1790890 .

[32] D. Chelazzi, R. Giorgi, P. Baglioni, Microemulsions, micelles, and functional gels: how colloids and soft matter preserve works of art, Angew. Chem. Int. Ed Engl. 57 (2018) 7296-7303, https://doi.org/10.1002/anie.201710711.

[33] D. Chelazzi, R. Bordes, R. Giorgi, K. Holmberg, P. Baglioni, The use of surfactants in the cleaning of works of art, Curr. Opin. Colloid Interface Sci. 45 (2020) 108123, https://doi.org/10.1016/j.cocis.2019.12.007.

[34] M. Baglioni, R. Giorgi, D. Berti, P. Baglioni, Smart cleaning of cultural heritage: a new challenge for soft nanoscience, Nanoscale 4 (2012) 42, https://doi.org/ 10.1039/c1nr10911a.

[35] M. Baglioni, G. Poggi, Y. Jaidar Benavides, F. Martínez Camacho, R. Giorgi, P. Baglioni, Nanostructured fluids for the removal of graffiti-a survey on 17 commercial spray-can paints, J. Cult. Herit. (n.d.), doi: 10.1016/j. culher.2018.04.016.

[36] M. Baglioni, Y. Jáidar Benavides, A. Desprat-Drapela, R. Giorgi, Amphiphilebased nanofludis for the removal of styrene/acrylate coatings: cleaning of stucco decoration in the Uaxactun archeological site (Guatemala), J. Cult. Herit. 16 (2015) 862-868, https://doi.org/10.1016/j.culher.2015.03.008.

[37] M. Baglioni, J.A.L. Domingues, E. Carretti, E. Fratini, D. Chelazzi, R. Giorgi, P. Baglioni, Complex fluids confined into semi-interpenetrated chemical hydrogels for the cleaning of classic art: a rheological and SAXS study, ACS Appl. Mater. Interfaces (2018), https://doi.org/10.1021/acsami.8b01841.

[38] N. Bonelli, C. Montis, A. Mirabile, D. Berti, P. Baglioni, Restoration of paper artworks with microemulsions confined in hydrogels for safe and efficient removal of adhesive tapes, Proc. Natl. Acad. Sci. 115 (2018) 5932-5937, https://doi.org/10.1073/pnas.1801962115.

[39] R. Mastrangelo, C. Montis, N. Bonelli, P. Tempesti, P. Baglioni, Surface cleaning of artworks: structure and dynamics of nanostructured fluids confined in polymeric hydrogel networks, Phys. Chem. Chem. Phys. 19 (2017) $23762-$ 23772, https://doi.org/10.1039/C7CP02662E.

[40] A. Mirabile, D. Chelazzi, P. Ferrari, C. Montis, D. Berti, N. Bonelli, R. Giorgi, P. Baglioni, Innovative methods for the removal, and occasionally care, of pressure sensitive adhesive tapes from contemporary drawings, Herit. Sci. 8 (2020) 42, https://doi.org/10.1186/s40494-020-00387-y.

[41] L. Pensabene Buemi, M.L. Petruzzellis, D. Chelazzi, M. Baglioni, R. Mastrangelo, R. Giorgi, P. Baglioni, Twin-chain polymer networks loaded with nanostructured fluids for the selective removal of a non-original varnish from Picasso's “L'Atelier” at the peggy guggenheim collection, venice, Herit Sci. 8 (2020), https://doi.org/10.1186/s40494-020-00420-0.

[42] R. Mastrangelo, D. Chelazzi, G. Poggi, E. Fratini, L. Pensabene Buemi, M.L. Petruzzellis, P. Baglioni, Twin-chain polymer hydrogels based on poly(vinyl alcohol) as new advanced tool for the cleaning of modern and contemporary art, Proc. Natl. Acad. Sci. U. S. A. 117 (2020) 7011-7020, https://doi.org/ 10.1073/pnas.1911811117.

[43] A. Bartoletti, R. Barker, D. Chelazzi, N. Bonelli, P. Baglioni, J. Lee, L.V. Angelova, B. Ormsby, Reviving WHAAM! a comparative evaluation of cleaning systems for the conservation treatment of Roy Lichtenstein's iconic painting, Herit. Sci. 8 (2020) 9, https://doi.org/10.1186/s40494-020-0350-2.

[44] A. Bartoletti, T. Maor, D. Chelazzi, N. Bonelli, P. Baglioni, L.V. Angelova, B.A. Ormsby, Facilitating the conservation treatment of Eva Hesse's Addendum through practice-based research, including a comparative evaluation of novel cleaning systems, Herit. Sci. 8 (2020) 35, https://doi.org/10.1186/s40494-02000378-z.

[45] K. Holmberg, B. Jönsson, B. Kronberg, B. Lindman, Surfactants and polymers in aqueous solution, Wiley, 2002.

[46] M. Raudino, G. Selvolini, C. Montis, M. Baglioni, M. Bonini, D. Berti, P. Baglioni, Polymer films removed from solid surfaces by nanostructured fluids: microscopic mechanism and implications for the conservation of cultural heritage, ACS Appl. Mater. Interfaces 7 (2015) 6244-6253, https://doi.org/ 10.1021/acsami.5b00534.

[47] M. Baglioni, C. Montis, F. Brandi, T. Guaragnone, I. Meazzini, P. Baglioni, D. Berti, Dewetting acrylic polymer films with water/propylene carbonate/surfactant mixtures - implications for cultural heritage conservation, Phys. Chem. Chem. Phys. 19 (2017) 23723-23732, https://doi. org/10.1039/C7CP02608K.

[48] M. Baglioni, C. Montis, D. Chelazzi, R. Giorgi, D. Berti, P. Baglioni, Polymer film dewetting by water/surfactant/good-solvent mixtures: a mechanistic insight and its implications for the conservation of cultural heritage, Angew. Chem. Int. Ed. 57 (2018) 7355-7359, https://doi.org/10.1002/anie.201710930.

[49] C. Montis, K. Koynov, A. Best, M. Baglioni, H.-J. Butt, D. Berti, P. Baglioni, Surfactants mediate the dewetting of acrylic polymer films commonly applied to works of art, ACS Appl. Mater. Interfaces 11 (2019) 27288-27296, https:// doi.org/10.1021/acsami.9b04912.

[50] M. Baglioni, M. Alterini, D. Chelazzi, R. Giorgi, P. Baglioni, Removing polymeric coatings with nanostructured fluids: influence of substrate, nature of the film, and application methodology, Front. Mater. 6 (2019), https://doi.org/10.3389/ fmats.2019.00311.

[51] M. Raudino, N. Giamblanco, C. Montis, D. Berti, G. Marletta, P. Baglioni, Probing the cleaning of polymeric coatings by nanostructured fluids: a QCM-D study, Langmuir 33 (2017) 5675-5684, https://doi.org/10.1021/acs. langmuir.7b00968.

[52] J.A.L. Domingues, N. Bonelli, R. Giorgi, E. Fratini, F. Gorel, P. Baglioni, Innovative hydrogels based on semi-interpenetrating p(HEMA)/PVP networks for the cleaning of water-sensitive cultural heritage artifacts, Langmuir 29 (2013) 2746-2755, https://doi.org/10.1021/la3048664.

[53] J. Domingues, N. Bonelli, R. Giorgi, E. Fratini, P. Baglioni, Innovative method for the cleaning of watersensitive artifacts: synthesis and application of highly retentive chemical hydrogels, Int. J. Conserv. Sci. 4 (2013) 715-722.

[54] J. Domingues, N. Bonelli, R. Giorgi, P. Baglioni, Chemical semi-IPN hydrogels for the removal of adhesives from canvas paintings, Appl. Phys. A. 114 (2013) 705-710, https://doi.org/10.1007/s00339-013-8150-0.

[55] C. Mazzuca, G. Poggi, N. Bonelli, L. Micheli, P. Baglioni, A. Palleschi, Innovative chemical gels meet enzymes: a smart combination for cleaning paper artworks, J. Colloid Interface Sci. 502 (2017) 153-164, https://doi.org/ 10.1016/j.jcis.2017.04.088.

[56] N. Bonelli, G. Poggi, D. Chelazzi, R. Giorgi, P. Baglioni, Poly(vinyl alcohol)/poly (vinyl pyrrolidone) hydrogels for the cleaning of art, J. Colloid Interface Sci. 536 (2019) 339-348, https://doi.org/10.1016/j.jcis.2018.10.025.

[57] N. Bonelli, D. Chelazzi, M. Baglioni, R. Giorgi, P. Baglioni, Confined aqueous media for the cleaning of cultural heritage: innovative gels and amphiphilebased nanofluids, in: P. Dillmann, L. Bellot-Gurlet, I. Nenner (Eds.), Nanosci. Cult. Herit., Atlantis Press, 2016, pp. 283-311, https://doi.org/10.2991/978-946239-198-7_10.

[58] R. Giorgi, M. Baglioni, P. Baglioni, Nanofluids and chemical highly retentive hydrogels for controlled and selective removal of overpaintings and undesired graffiti from street art, Anal. Bioanal. Chem. (2017) 1-6, https://doi.org/ 10.1007/s00216-017-0357-z

[59] F. Mizia, M. Notari, F. Rivetti, U. Romano, C. Zecchini, Carbonati alchilici: solventi della nuova generazione, Chim. Ind. 83 (2001) 47-54. 
[60] W.E. Vargas, G.A. Niklasson, Applicability conditions of the Kubelka-Munk theory, Appl. Opt. 36 (1997) 5580-5586, https://doi.org/10.1364/ A0.36.005580.

[61] M.T. Doménech-Carbó, A. Doménech-Carbó, J.V. Gimeno-Adelantado, F. BoschReig, Identification of synthetic resins used in works of art by fourier transform infrared spectroscopy, Appl. Spectrosc. 55 (2001) 1590-1602, https://doi.org/ $10.1366 / 0003702011954152$.

[62] F. Govaert, M. Bernard, Discriminating red spray paints by optical microscopy, Fourier transform infrared spectroscopy and X-ray fluorescence, Forensic Sci. Int. 140 (2004) 61-70, https://doi.org/10.1016/j.forsciint.2003.11.015.

[63] T. Learner, Modern paints: uncovering the choices, in: T. Learner, P. Smithen, J. Krueger, M.R. Schilling (Eds.), Mod. Paints Uncovered Proc. Mod. Paints Uncovered Symp., Getty Conservation Institute, Los Angeles, 2007.

[64] F.A. Andersen, L. Brečević, G. Beuter, D.B. Dell'Amico, F. Calderazzo, N.J. Bjerrum, A.E. Underhill, Infrared spectra of amorphous and crystalline calcium carbonate, Acta Chem. Scand. 45 (1991) 1018-1024, https://doi.org/10.3891/ acta.chem.scand.45-1018.

[65] R. Ploeger, D. Scalarone, O. Chiantore, The characterization of commercial artists' alkyd paints, J. Cult. Herit. 9 (2008) 412-419, https://doi.org/10.1016/j. culher.2008.01.007.

[66] D.O. Hummel, Atlas of plastics additives: analysis by spectrometric methods, Springer-Verlag, Berlin Heidelberg, 2002, doi: 10.1007/978-3-642-56211-2.

[67] D. Scalarone, O. Chiantore, Separation techniques for the analysis of artists' acrylic emulsion paints, J. Sep. Sci. 27 (2004) 263-274, https://doi.org/ 10.1002/jssc.200301638.

[68] M. Melchiorre Di Crescenzo, E. Zendri, C. Miliani, F. Rosi, A preliminary FTIRbased exploration of the surfactant phase-separation process in contemporary mural paintings, E-Preserv. Sci. 10 (2013) 10-18.

[69] S. Vahur, A. Teearu, P. Peets, L. Joosu, I. Leito, ATR-FT-IR spectral collection of conservation materials in the extended region of $4000-80 \mathrm{~cm}^{-1}$, Anal. Bioanal. Chem. 408 (2016) 3373-3379, https://doi.org/10.1007/s00216-016-9411-5.

[70] Ş. Uğur, Ö. Pekcan, Fluorescence technique to study thickness effect on dissolution of latex films, J. Appl. Polym. Sci. 77 (2000) 1087-1095, https://doi. org/10.1002/1097-4628(20000801)77:5<1087::AID-APP16>3.0.CO;2-K.

[71] M.A. Winnik, Latex film formation, Curr. Opin. Colloid Interface Sci. 2 (1997) 192-199, https://doi.org/10.1016/S1359-0294(97)80026-X.

[72] P.A. Steward, J. Hearn, M.C. Wilkinson, An overview of polymer latex film formation and properties, Adv. Colloid Interface Sci. 86 (2000) 195-267, https://doi.org/10.1016/S0001-8686(99)00037-8.

[73] Y. Chevalier, C. Pichot, C. Graillat, M. Joanicot, K. Wong, J. Maquet, P. Lindner, B. Cabane, Film formation with latex particles, Colloid Polym. Sci. 270 (1992) 806-821, https://doi.org/10.1007/BF00776153.

[74] P. Ferrari, D. Chelazzi, N. Bonelli, A. Mirabile, R. Giorgi, P. Baglioni, Alkyl carbonate solvents confined in poly (ethyl methacrylate) organogels for the removal of pressure sensitive tapes (PSTs) from contemporary drawings, J. Cult. Herit. 34 (2018) 227-236, https://doi.org/10.1016/j.culher.2018.05.009.

[75] W. von Rybinski, K. Hill, Alkyl polyglycosides-properties and applications of a new class of surfactants, Angew. Chem. Int. Ed. 37 (1998) 1328-1345, https:// doi.org/10.1002/(SICI)1521-3773(19980605)37:10<1328::AID-ANIE1328>3.0. CO;2-9.

[76] N. Villandier, A. Corma, Transformation of cellulose into biodegradable alkyl glycosides by following two different chemical routes, ChemSusChem. 4 (2011) 508-513, https://doi.org/10.1002/cssc.201000371.

[77] S. Matsumura, K. Imai, S. Yoshikawa, K. Kawada, T. Uchibor, Surface activities, biodegradability and antimicrobial properties of n-alkyl glucosides, mannosides and galactosides, J. Am. Oil Chem. Soc. 67 (1990) 996-1001, https://doi.org/10.1007/BF02541865.

[78] S.S. Talmage, Environmental and human safety of major surfactants: alcohol ethoxylates and alkylphenol ethoxylates, CRC Press, 1994.

[79] J. Steber, P. Wierich, Metabolites and biodegradation pathways of fatty alcohol ethoxylates in microbial biocenoses of sewage treatment plants, Appl. Environ. Microbiol. 49 (1985) 530-537.
[80] M. Huber, U. Meyer, P. Rys, Biodegradation mechanisms of linear alcohol ethoxylates under anaerobic conditions, Environ. Sci. Technol. 34 (2000) 1737-1741, https://doi.org/10.1021/es9903680.

[81] T. Balson, M.S.B. Felix, Biodegradability of non-ionic surfactants, in: D.R. Karsa, M.R. Porter (Eds.), Biodegrad. Surfactants, Springer, Netherlands, Dordrecht, 1995, pp. 204-230, https://doi.org/10.1007/978-94-011-1348-9_7.

[82] Y.C. Liu, C.Y. Ku, P. LoNostro, S.H. Chen, Ion correlations in a micellar solution studied by small-angle neutron and x-ray scattering, Phys. Rev. E. 51 (1995) 4598-4607, https://doi.org/10.1103/PhysRevE.51.4598.

[83] E.Y. Sheu, S.H. Chen, Thermodynamic analysis of polydispersity in ionic micellar systems and its effect on small-angle neutron scattering data treatment, J. Phys. Chem. 92 (1988) 4466-4474, https://doi.org/10.1021/ j100326a044.

[84] S.R. Kline, Reduction and analysis of SANS and USANS data using IGOR Pro, J. Appl. Crystallogr. 39 (2006) 895-900, https://doi.org/10.1107/ S0021889806035059.

[85] V. Degiorgio, M. Corti, S. italiana di fisica, Physics of amphiphiles-micelles, vesicles, and microemulsions: Varenna on Lake Como, Villa Monastero, 19-29 July 1983, North-Holland, 1985.

[86] M. Baglioni, M. Raudino, D. Berti, U. Keiderling, R. Bordes, K. Holmberg, P. Baglioni, Nanostructured fluids from degradable nonionic surfactants for the cleaning of works of art from polymer contaminants, Soft Matter. 10 (2014) 6798-6809, https://doi.org/10.1039/C4SM01084A.

[87] Y. Liu, W.-R. Chen, S.-H. Chen, Cluster formation in two-Yukawa fluids, J. Chem. Phys. 122 (2005), https://doi.org/10.1063/1.1830433 044507.

[88] M. Broccio, D. Costa, Y. Liu, S.-H. Chen, The structural properties of a twoYukawa fluid: simulation and analytical results, J. Chem. Phys. 124 (2006), https://doi.org/10.1063/1.2166390 084501.

[89] S.-H. Chen, M. Broccio, Y. Liu, E. Fratini, P. Baglioni, The two-Yukawa model and its applications: the cases of charged proteins and copolymer micellar solutions, J. Appl. Crystallogr. 40 (2007) s321-s326, https://doi.org/10.1107/ S0021889807006723.

[90] S. Kumar, M.-J. Lee, V.K. Aswal, S.-M. Choi, Block-copolymer-induced longrange depletion interaction and clustering of silica nanoparticles in aqueous solution, Phys. Rev. E. 87 (2013), https://doi.org/10.1103/PhysRevE.87.042315.

[91] J. Xiao, W. Li, Study on osmotic pressure of non-ionic and ionic surfactant solutions in the micellar and microemulsion regions, Fluid Phase Equilibria 263 (2008) 231-235, https://doi.org/10.1016/j.fluid.2007.10.009.

[92] S. Martellucci, A.N. Chester, Progress in microemulsions, Springer Science \& Business Media, 2013.

[93] L. Reatto, M. Tau, A statistical model for non-ionic micellar solutions and their phase diagrams, Chem. Phys. Lett. 108 (1984) 292-296, https://doi.org/ 10.1016/0009-2614(84)87067-0.

[94] M. Kotlarchyk, S.-H. Chen, Analysis of small angle neutron scattering spectra from polydisperse interacting colloids, J. Chem. Phys. 79 (1983) 2461-2469, https://doi.org/10.1063/1.446055.

[95] G. Palazzo, D. Fiorentino, G. Colafemmina, A. Ceglie, E. Carretti, L. Dei, P. Baglioni, Nanostructured fluids based on propylene carbonate/water mixtures, Langmuir 21 (2005) 6717-6725, https://doi.org/10.1021/la050492z.

[96] G. Colafemmina, D. Fiorentino, A. Ceglie, E. Carretti, E. Fratini, L. Dei, P. Baglioni, G. Palazzo, Structure of SDS micelles with propylene carbonate as cosolvent: a PGSE-NMR and SAXS study, J. Phys. Chem. B. 111 (2007) 71847193, https://doi.org/10.1021/jp0688761.

[97] M. Baglioni, D. Berti, J. Teixeira, R. Giorgi, P. Baglioni, Nanostructured surfactant-based systems for the removal of polymers from wall paintings: a small-angle neutron scattering study, Langmuir 28 (2012) 15193-15202, https://doi.org/10.1021/la303463m.

[98] C. Tanford, The hydrophobic effect: formation of micelles and biological membranes, second ed., Wiley, New York, 1980. 